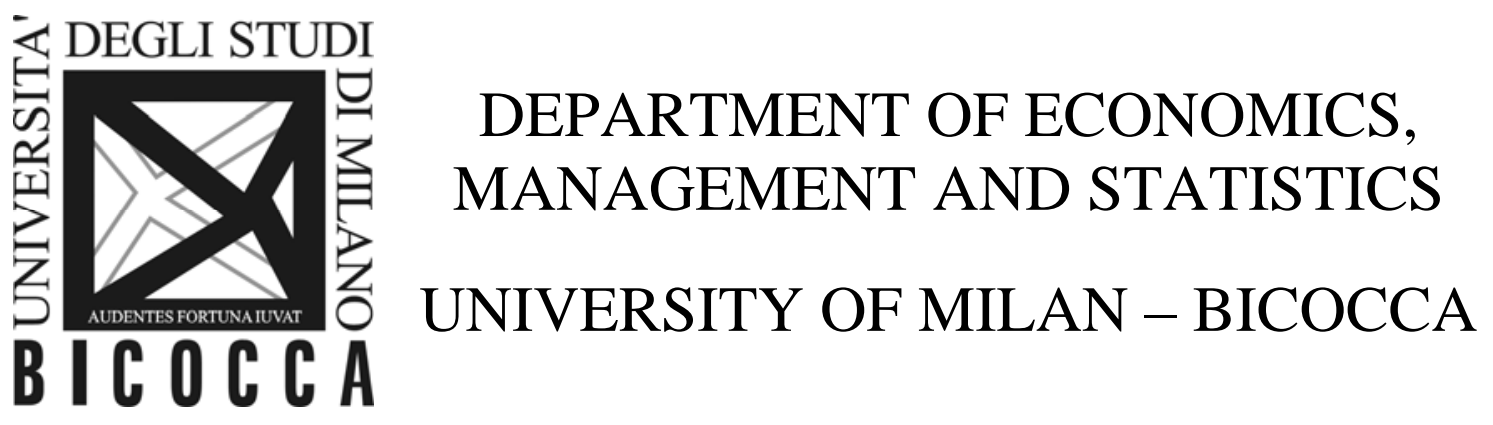

DEMS WORKING PAPER SERIES

Social comparison and risk taking behavior

Astrid Gamba, Elena Manzoni

No. 266 - January 2014

Dipartimento di Economia, Metodi Quantitativi e Strategie di Impresa

Università degli Studi di Milano - Bicocca

http://dems.unimib.it/ 


\title{
Social comparison and risk taking behavior*
}

\author{
Astrid Gamba and Elena Manzoni \\ Department of Economics \\ University of Milan Bicocca
}

January 24, 2014

\begin{abstract}
We study theoretically and experimentally decision making under uncertainty in a social environment. We introduce an interdependent preferences model that assumes that the decision maker evaluates monetary outcomes in relation both with his individual and his social reference point. In the experiment we reproduce a workplace environment whereby subjects interact in an effort task, earn (possibly) different wages from this task and then undertake a risky decision that may give them an extra bonus. Controlling for intrinsic risk attitudes, we find that both downward and upward social comparison strongly influence risk attitudes and that they both generate more risk loving behavior. Moreover, we find that a propension to envy counterposes such effect, by increasing risk aversion.
\end{abstract}

Keywords: Social comparison, risk aversion, interdependent preferences, reference point. JEL classification: C91, D03, D81.

*We are grateful to the Max Planck Institute of Economics (Jena) for financial support and Ria Stangneth and Claudia Zellman for technical assistance in the lab. We thank Madhav Aney, Lorenzo Cappellari, Andrew Clark, Anna Conte, Paolo Crosetto, Anna De Paoli, Werner Güth, Jona Linde, Fabio Maccheroni, Aldo Rustichini, Luca Stanca and participants of the Thurgau Experimental Economics Meeting 2013 (Konstanz) for useful suggestions. The usual disclaimer applies. Elena Manzoni gratefully acknowledges financial support from PRIN 2010-2011 "New Approaches to political economy: positive political theories, empirical evidence and experiments in laboratory". 


\section{Introduction}

The relevance of social comparison to explain human behavior has been extensively aknowledged both in economics and in other disciplines. For example, in social psychology, according to the Social Comparison Theory by Festinger (1954), people evaluate their own opinions and abilities in comparison with opinions and abilities of others. In the economic literature, Veblen (1899) in his Theory of the Leisure Class introduced the idea that individuals care about comparison with other members of the same community and conspicuous consumption is a way to gain and signal social status. Duesenberry (1949) also discussed the relevance of social influence on consumption. Many studies thereafter in the macroeconomic and asset pricing literature consider social comparison as a determinant of individual decisions by assuming that agents care not only about their absolute level of consumption, but also about their relative position with respect to the aggregate consumption of the society, the so called keeping up with the Joneses phenomenon. Moreover, economists have provided empirical evidence that relative income has an impact on job satisfaction (Clark and Oswald, 1996; Card et al., 2012) and happiness (Ferrer-i-Carbonell, 2005; Vendrik and Woltjer, 2007). More recently, a strand of the economic literature has focused on the behavioral implications of wage comparison in labor market relations, studying, in particular, how wage inequality affects effort or performance (Charness and Kuhn, 2007; Clark et al., 2010; Cohn et al. 2011; Ockenfels et al. 2010).

Still, few studies have investigated the mechanisms through which social comparison affects individual decision processes. In this paper, we study, theoretically and experimentally, whether and how social comparison affects decision making under uncertainty. We adopt an interdependent preferences model that assumes that a comparison outcome, the monetary outcome of a reference group, enters the utility function of the decision maker. We apply our model to an experimental labor relation setting, whereby workers earn a wage from an effort task and, being informed about their co-worker's wage, have to take a decision that involves uncertain monetary outcomes in order to increase their earnings.

Given the large body of empirical evidence on the relevance of social comparison for the well-being of the individuals, it is natural to consider that, when evaluating the (probabilistic) consequences of their decisions (e.g., investment decisions), agents do not care solely about their own monetary outcome but also about their relative outcome with respect to their peers. This implies that the social condition of the decision maker (his status) and his disposition toward social gains and social losses may affect his attitude toward risk. Since the seminal paper by Kahneman and Tversky (1979), it is well aknowledged that, in a private environment, individuals have different risk attitudes depending on whether they face prospects that are positive or negative variations with respect to a certain reference point (e.g., status quo, goal etc.). Similarly, in a social environment it may occur that individuals have different risk attidudes depending on whether the prospects they face are above or below the outcome of the reference group (e.g., colleagues, neighbours, relatives etc.). Indeed, individuals may not only dislike the risk that regards their standing with respect to a social referent (social risk aversion), but they may also dislike such risk with different intensities when they are in a social losses condition with respect to when they are in a social gains condition. For example, it may occur that individuals facing a disadvantageous social condition are willing to take more risks than individuals facing an advantageous social condition, because they are driven by the incentive to catch up with their social referent. It may also occur that the further above they are with respect to the outcome of their social referent, the less they dislike risks on their relative standing.

The most general approach to social comparison and decision making is the model of social 
decision theory introduced by Maccheroni et al. (2012). The authors provide an axiomatic foundation to interdependent preferences and provide a representation that incorporates as special cases many functional forms that have been adopted by the empirical literature to describe relative income concerns. ${ }^{1}$ Maccheroni et al. (2012) assume that the value function of a decision maker depends not only on the intrinsic utility that he derives from the outcome of his decision but also on the satisfaction he derives from comparing his outcome with the outcomes of the members of his reference group.

As in Maccheroni et al. (2012), we adopt an additive representation of the utility function of the decision maker, that consists of an individual and a social component. We adapt this representation to our economic setting by incorporating features of prospect theory (Kahneman and Tversky, 1979). Indeed, we express both the private and the social component as functions of the (monetary) deviations with respect to a reference point. While the individual component is a function of the positive variation with respect to an individual reference point (e.g., status quo, goals, etc.), the social component is a function of the positive or negative variations with respect to a social reference point (e.g., the monetary outcome of the reference group). This specification reflects the assumption that both internal and external habits matter in the decision making process. While in the theoretical part we do not take any explicit assumption on the nature of the individual reference point, in the experiment we assume that it is the wage the worker earns from an effort task, which corresponds to the fixed part of the worker's final earnings. We impose as a social reference point the final earnings of the co-worker.

As the decision under risk that the worker has to face involves only outcomes that are positive variations with respect to his wage, the decision problem is constantly framed in the individual gains domain. Instead, we let the positioning of the decision maker's final outcome to vary with respect to his social reference point, as the worker's final earnings fall either above (social gains) or below (social losses) his co-worker's final earnings.

The basic intuition of our model is that, for a given intrinsic disposition toward risk, the relative position of the individual outcome with respect to the social referent's outcome (his social condition) and the curvature of the social component of the utility function induce different risk attitudes.

The model of decision making in a social context that is closer to our paper is the comparison utility model of Clark and Oswald (1998), whereby the utility of a decision maker depends not only on his own action but also on the comparison with the action taken by others. In that setting, the social component of the utility function is expressed as a function of the deviations of the agent's behavior from his peers' behavior and different curvatures of the social component of the utility function determine different attitudes towards others' actions, as conformism or deviance. Differently, in our setting, the social component is expressed as a function of the deviations of the agent's monetary outcome from his peers' outcome. However, as in their setting, different curvatures of the social component may have different behavioral implications.

In the theoretical part, we analyze the behavioral implications of a comparison-concave and of a comparison-convex social component and we focus on the implications of a social component that displays the usual prospect theory properties, i.e., convexity in the social losses domain and concavity in the social gains domain.

In the experimental part, we study whether and how social comparison influences risk taking behavior, by varying the social condition in which the decision maker finds himself when he has to take the risky decision.

In the first part of the experiment, we elicit intrinsic risk attitudes through a graphical

\footnotetext{
${ }^{1}$ For an axiomatization of the relative income criterion see also Ok and Koçkesen (2000).
} 
version of the Multiple Price List (MPL) format (Holt and Laury, 2002). In the second part of the experiment, we reproduce a social environment, whereby randomly paired subjects interact in a real effort task (hereafter, work task). For completing this task, workers earn a fixed wage, which can be either low or high and may coincide or differ from the wage assigned to their co-worker. After being informed about both their own wage and the wage of their co-worker, subjects face another MPL format (with different stakes). Through this second risk task, that we call bonus task, workers can get an extra gain (the bonus) on top of their wage. We pay the bonus task only to one worker in each pair; this selection is performed at the end of the experiment through a random draw. Hence, when facing the bonus task, each worker is aware that, when his decision is effective, i.e., he gets the bonus, his co-worker's final earnings must coincide with his co-worker's wage. This payment scheme allows us to fix the worker's social reference point at the co-worker's wage level. Therefore, by simply manipulating wages allocations across pairs, we can reproduce various social conditions. There are social conditions where all possible final earnings (the wage plus the bonus) of a worker are above the social reference point (social gains), and social conditions where all possible final earnings are below the social reference point (social losses).

It is worth noticing that, since we are interested in the effects of social comparison per se, we treat the worker's social condition in the bonus task as exogenously given: the worker's position in the (pairwise) social ranking is fixed and it is not determined by the worker's decisions in the bonus task. $^{2}$ First, every possible bonus is not large enough to allow him to move from a regime of social losses to a regime of social gains. Secondly, the worker's choice does not produce any effect on the final outcome of his co-worker, which coincides with the co-worker's wage from the work task. Notice that, besides keeping the social ranking fixed, this second aspect of the design also allows us to rule out social concerns that the decision maker might have if he had to decide for the payoff of the other.

We study how different social situations affect the worker's risk taking behavior in the bonus task, by performing a between subjects analysis.

We find that the decision maker's social condition when facing the bonus task does indeed affect his risk taking behavior. When we control for subjects' intrinsic risk attitudes, as elicited in the first risk task, we see that in the social environment subjects are on average more risk averse in a situation of small social gains, than they are when they face situations of social losses or large social gains. These results are compatible with an utility function that displays concavity in its individual component and prospect theory features in its social component, i.e., convexity in the social losses domain and concavity in the social gains domain.

To the best of our knowledge, there are only few other laboratory experiments that investigate the effects of social comparison on risk attitudes. Bolton and Ockenfels (2010) perform an experiment in which subjects face choices under uncertainty both in an individual and in a social context. While in the individual context subjects face binary lottery choices, in the social context they face dictator choice problems with uncertain payoffs. The authors study how the advantageous or disadvantageous inequality in the payoff allocations of either the safe or the risky option affect the decision maker's risk attitude. Notice that the focus of this study is different from ours: while in their experiment the decision maker's choice influences the payoff of the other person, in ours the payoff of the other person is exogenously given. In our scenario, given his (fixed) position in the pairwise social ranking, the individual can only change (increase or decrease) the distance between his final outcome and the final outcome of his peer and he

\footnotetext{
${ }^{2}$ For an experimental analysis of the relation between risk attitudes and the decision maker's possibility of influencing the social ranking see Schwerter (2013).
} 
can do that only by acting on his own payoff.

Rohde and Rohde (2011) study decision making under uncertainty in a social context and show that risk taking is affected by the risks faced by other persons. Also this study differs from ours, as in our experiment the outcome of the social referent is certain, when the decision maker faces the risky decision.

In the experiment of Rustichini et al. (2008) subjects face binary lottery choices, being informed about the choices made by other subjects. By measuring subjects' emotional valuations and physiological responses, the authors conclude that social gains loom larger than social losses, contrary to prospect theory predictions. Interestingly, they also find that, when a decision maker faces a competitor with lower earnings, he is more willing to take risks. The main difference with our experiment is that, our decision makers are not informed about their peer's choice. This different aspect of the design corresponds to a different definition of social comparison and, hence, of the social reference point: we assume that the decision maker compares his possible final monetary outcomes (his final status) with the fixed monetary outcome of his co-worker (the co-worker's status), ruling out any possible comparison with the co-worker's behavior.

Fafchamps et al. (2013) explore, among other things, the effect of social comparison on risk taking behavior in a multi-rounds experiment on asset integration. The evidence suggests that there might be a keeping up with the winners effect that triggers risk taking behavior by subjects who receive an initial endowment to invest which is relatively lower than the endowment received by the other subjects.

In the experimental work that is closest to our paper, Linde and Sonnemans (2012) study the effect on risk taking behavior of social comparison per se. Through a within subjects design and a risk elicitation procedure different from the one we implemented, the authors study the effect of different social conditions on risk attitudes. They find that risk aversion decreases as subjects moves from a social losses regime to a neutral regime and decreases even more in a social gains regime. In the final discussion we provide a possible explanation for the differences between their results and ours, which we believe they are generated by substantial differences in the experimental setting.

\section{Theoretical framework}

We consider the problem of a decision maker, whom we call agent 1, who has to choose among risky prospects. Let $\mathbb{X} \in \mathbb{R}$ be the set of possible outcomes.

Definition 1 A prospect for agent 1 is a contract $\left(\mathbf{x}_{\mathbf{1}}, p_{1} ; \ldots ; \mathbf{x}_{l}, p_{l}\right)$ that yields with probability $p_{i}$ an outcome $\mathbf{x}_{i} \in \mathbb{X}$ for agent 1 .

In this paper we investigate how the decision maker's risk attitudes are affected by his relative position within his group of peers. For this reason, we model his choices as made in an environment where there are $n-1$ other agents. Each agent $j \in\{2, \ldots, n\}$ has a fixed outcome $x_{j} \in \mathbb{X}$, that does not depend on the decision maker's choice.

We assume that the decision maker's preferences over the final outcomes are influenced by two characteristics of the choice situation, an individual reference point, $r$, and a social reference point, $s$.

The need for an individual reference point is well documented in the literature, both from the theoretical and experimental points of view. Starting from the seminal work of Kahneman and Tversky (1979), a large number of papers have analyzed the behavior of decision makers 
who compare their final outcomes to an individual reference point, which can be either derived from the description of the decision problem, or endogenously determined in equilibrium (as in Koszegi and Rabin, 2006, 2007). Moreover, a recent strand of literature considers how the decision makers' attitudes are influenced by the presence of multiple individual reference points (see, for example, Wang and Johnson, 2012 and March and Shapira, 1992). Also the experimental literature such as Sullivan and Kida (1995), Ordonez et al. (2000) and Koop and Johnson (2010) investigates the behavior of agents that simultaneously consider multiple reference points, e.g., the status quo and the individual goals.

For simplicity, however, we assume that, for a given decision problem, there is a unique individual reference point $r .^{3}$

We follow the literature on multiple reference points in a different way, by introducing a social reference point $s \in \mathbb{X}$. We assume that the social reference point $s$ is determined from the outcomes of the agents in the set $\{2,3, \ldots, n\} .{ }^{4}$ Reasonable assumptions for the characterization of $s$ can be the average of the outcomes of these agents, their median, their minimum, or their maximum. Notice that if $n=2$, as we will impose in our experiment, all these possible candidates for $s$ coincide with the outcome of agent 2 .

We classify prospects in three categories, according to their relation with the social reference point.

Definition 2 A prospect has social gains if its outcomes are all greater than the social reference point $s_{i}$ in each state $i$; a prospect has social losses if its outcomes are all lower than the social reference point $s_{i}$ in each state $i$; a prospect is mixed in all other cases.

In our analysis we consider only choice situations with prospects that display social gains or social losses, whereby the position of the decision maker in the social ranking is constant across outcomes. As we want to investigate the effects that the decision maker's social condition per se has on his risk attitudes, it is convenient to avoid choice situations where the decision maker's social condition is outcome dependent and, hence, endogenously determined by the decision maker's choice.

We aknowledge that in some economic contexts the competition for a higher status within a social group could generate a pressure that may affect the decision maker's propension to take risks. However, in real life, most of the investment decisions that an individual faces do not have economic consequences that are large enough to change substantially his social status. Nonetheless, even in the typical choice situation where the social ranking is unquestionable and the individual can only get closer or move further away from his peers' status, concerns for the higher economic status of the peers or for the lower economic status of the peers can shape the individual's risk attitude.

The existing literature on social comparison and decision making provides no empirical support in favor of a specific functional form for the agents' value function. Therefore we model the decision maker's preferences through a function that is characterized by two additive components, one that describes his concern for an individual reference point, and the other that takes into account the influence of the social reference point. Additivity of the value

\footnotetext{
${ }^{3}$ Therefore we do not allow for multiple $r$, nor for and individual reference point that is endogeously determined in equilibrium.

${ }^{4}$ For simplicity of analysis we assume $s$ to be state independent. However, our theoretical framework is compatible with a state-dependent social reference point, as long as $s$ is independent of the decision maker's choices. In the event of a social reference point that depends on the decision maker's choices other consideration may affect the utility function.
} 
function in these two components is the simplest assumption that can be made to describe choice situations where both internal and external habits play a role. Such assumption is in line with the comparison utility by Clark and Oswald (1998) and with the model of interdependent preferences by Maccheroni et al. (2012). In the latter, the value function associated to a profile of acts consists of a first term, that concerns the agent's intrinsic (expected) utility from the realized outcome, and a second term, that represents the agent's satisfaction from the comparison of his outcome with the distribution of outcomes in his reference group. In its general form, the representation of Maccheroni et al. (2012) only assumes that this second term is (stochastically) decreasing in the distribution of outcomes of the agent's reference group.

In our specification, the intrinsic utility is represented as a function of the deviations of the agent's monetary outcome from his individual reference point; the social component is instead a function of the deviations of the agent's monetary outcome from the monetary outcome of his social referent. The utility function that we introduce is as follows:

$$
v(x ; s, r)=u(x-r)+\gamma G(x-s)
$$

where $x$ is the monetary payoff of the individual, $r$ is the individual reference point, $s$ is the social reference point and $\gamma$ is a parameter that represents the concern for relative status, $\gamma \geq 0$. Given the utility function, the decision maker's value function associated to a prospect $x$ is:

$$
V\left(x_{1}, s_{1}, p_{1} ; \ldots ; x_{n}, s_{n}, p_{n}\right)=\sum_{i=1}^{n} p_{i} v\left(x_{i}, s_{i} ; r\right) .
$$

Our assumptions on the properties of the value function combine prospect theory features (Kahneman and Tversky, 1979) with the coexistence of two reference points. In case of a single reference point, prospect theory predicts that risk attitudes vary depending on whether prospects are perceived as losses (i.e., every outcome is smaller than the reference point) or as gains (i.e., every outcome is larger than the reference point). In particular, a prospect theory value function is convex in the losses domain and concave in the gains domain, which implies that the decision maker displays risk loving behavior when facing losses and risk averse behavior when facing gains. Since the focus of this paper is on the effect that different social reference points induce on the risk attitudes of the decision maker, we fix the private environment to be the one with gains, by considering only prospects in which every outcome is greater than $r$ (individual gains). Therefore, we define the behavior of $u(\cdot)$ only in the region where $x>r$; in such region, we assume $u(x-r)$ to be increasing and concave $\left(u^{\prime}(y)>0\right.$ and $u^{\prime \prime}(y)<0$ for $y>0)$.

Instead, we let the social environment to be either a social gains or a social losses situation. We assume that the social component $G(\cdot)$ is increasing in $(x-s)$, which implies that the decision maker enjoys being above the social referent and he dislikes being below.

The curvature of the social component $G(\cdot)$ is crucial to understand the impact of social comparison on the decision maker's risk attitudes. In principle, we could consider $G(\cdot)$ functions which are either overall convex, overall concave or with a curvature which depends on the social domain. A direct application of prospect theory to the the $G(\cdot)$ would imply that its curvature does change across social domains and that $G(\cdot)$ is convex in the social losses domain (i.e., for prospects where $x<s$ ) and concave in the social gains domain (i.e., for prospects where $x>s$ ).

To study the effects that social comparison has on the risk attitudes of the decision maker, we analyze how the Arrow-Pratt coefficient of absolute risk aversion changes with the relative social position of the agent (i.e., with $s$, having fixed $x$ and $r$ ). The coefficient of risk aversion, 
$R A(x ; r, s)$, that depends both on the individual and the social reference point, is:

$$
R A(x ; r, s)=-\frac{u^{\prime \prime}(x-r)+\gamma G^{\prime \prime}(x-s)}{u^{\prime}(x-r)+\gamma G^{\prime}(x-s)}
$$

In order to analyze more easily how the risk attitudes change across social domains in relation to different curvatures of $G(\cdot)$, it is useful to introduce in a separate way the coefficient of risk aversion of the individual component $u(\cdot), R A^{u}$, which we assumed to be positive, and the coefficient of risk aversion of the social component $G(\cdot), R A^{G}$.

$$
R A^{u}(x-r)=-\frac{u^{\prime \prime}(x-r)}{u^{\prime}(x-r)}, \quad R A^{G}(x-s)=-\frac{G^{\prime \prime}(x-s)}{G^{\prime}(x-s)} .
$$

We call $R A^{u}$ private risk aversion and, adopting the language of Maccheroni et al. (2012), we call $R A^{G}$ social risk aversion. Private risk aversion describes how much the decision maker dislikes the risk that concerns the standing of his (final) outcome with respect to his individual reference point. Similarly, social risk aversion conveys the idea that the decision maker dislikes the risk that regards the standing of his final outcome with respect to the social reference point.

It is possible to show that $R A(x ; r, s)>R A^{u}(x-r)$ if and only if $R A^{G}(x-s)>R A^{u}(x-r) .^{5}$ That is, the decision maker is overall more risk averse in a social context than he would be in a private context if and only if his social risk aversion prevails on his private risk aversion, i.e., he dislikes more to take risks on his social distance than on the distance with respect to his individual reference point. This relation implies that for comparison-linear and comparisonconvex value functions it is always true that $R A(x ; r, s)<R A^{u}(x-r)$, since for such functions $R A^{G}(x-s)<R A^{u}(x-r)$ for every $x, r$ and $s$, given the concavity of $u(\cdot)$.

However, our object of interest lies beyond the simple comparison between the general coefficient of risk aversion $R A$ and the coefficients of risk aversion of its two components, $R A^{G}$ and $R A^{u}$. We are indeed interested in how the coefficient of risk aversion $R A$ varies as the external reference point $s$ changes. The following propositions present the results for comparison-linear, comparison-convex and comparison-concave value functions. The proofs are contained in the Appendix.

Proposition 3 If the value function is comparison-linear, then $R A(x ; r, s)$ is constant in $s$.

This proposition implies that if the value function is comparison-linear the decision maker's risk attitudes do not vary across social conditions.

Proposition 4 If the value function is comparison-convex, the effect of $s$ on $R A(x ; r, s)$ is related to the behavior of $G(\cdot)$ in the following way:

(i) if $G(\cdot)$ displays constant absolute risk aversion (CARA), then $\frac{\partial R A(x ; r, s)}{\partial s}>0$ for every $x, r$ and $s$;

(ii) if $G(\cdot)$ displays decreasing absolute risk aversion (DARA), then $\frac{\partial R A(x ; r, s)}{\partial s}>0$ for every $x, r$ and $s$;

\footnotetext{
${ }^{5}$ This can be easily seen by rewriting the general coefficient of risk aversion as follows:

$$
R A(x ; r, s)=R A^{u}(x-r)-\frac{\gamma\left(u^{\prime}(x-r) G^{\prime \prime}(x-s)-u^{\prime \prime}(x-r) G^{\prime}(x-s)\right)}{u^{\prime}(x-r)\left(u^{\prime}(x-r)+\gamma G^{\prime}(x-s)\right)}
$$
}


Saying that $R A(x ; r, s)$ is increasing in $s$ implies that, for a fixed individual gain or loss $(x-r)$, risk aversion decreases the larger is the social gain and it increases the larger is the social loss. Notice that we cannot say anything conclusive about the relation between $R A(x ; r, s)$ and $s$ in case $G(\cdot)$ displays increasing absolute risk aversion (IARA).

Proposition 5 If the value function is comparison-concave, the effect of $s$ on $R A(x ; r, s)$ is related to the behavior of $G(\cdot)$ in the following way:

(i) if $G(\cdot)$ is $C A R A$, then $\frac{\partial R A(x ; r, s)}{\partial s}>0$ iff $R A^{G}(x-s)>R A^{u}(x-r)$;

(ii) if $G(\cdot)$ is DARA, then $\frac{\partial R A(x ; r, s)}{\partial s}>0$ if $R A^{G}(x-s)>R A^{u}(x-r)$;

(iii) if $G(\cdot)$ is IARA, then $\frac{\partial R A(x ; r, s)}{\partial s}<0$ if $R A^{G}(x-s)<R A^{u}(x-r)$.

Moreover, if $G(\cdot)$ is DARA, the following holds for any $x$ and $r: R A(x ; r, s)>R A^{u}(x-r)$ if $s>\hat{s}(x, r)$, and $R A(x ; r, s)<R A^{u}(x-r)$ if $s<\hat{s}(x, r)$, where $\hat{s}(x, r) \in(-\infty, \infty)$.

This implies that a comparison-concave value function (where $G(\cdot)$ is CARA or DARA) is associated with a coefficient of risk aversion that decreases in social gains (and increases in social losses) at least as long as $R A^{G}(x-s)>R A^{u}(x-r)$; moreover, a comparison-concave value function (where $G(\cdot)$ is IARA) is associated with a coefficient of risk aversion that increases in social gains (and decreases in social losses) at least as long as $R A^{G}(x-s)<R A^{u}(x-r)$.

Let us consider now a value function with a social component characterized by prospect theory features. We can first notice that the behavior in the social gains domain depends on whether the $G(\cdot)$ is CARA, DARA or IARA. We make the rather plausible assumption that $G(\cdot)$ is DARA, i.e., social risk aversion decreases in social gains. ${ }^{6}$

Proposition 6 Assume that $G(\cdot)$ is concave and DARA in social gains and convex in social losses. Consider a pair $(r, s)$ and take $x>\max (r, s)$. If $R A^{G}(x-s)>R A^{u}(x-r)$ then:

(i) $R A(x ; r, \hat{s})<R A(x ; r, s) \forall \hat{s}<s$;

(ii) $R A(x ; r, \hat{s})<R A(x ; r, s) \forall x<\hat{s}$.

\section{Proof.}

(i) Since in the social gains domain $G(\cdot)$ is DARA in $(x-s)$, it holds true that $R A^{G}(x-\hat{s})<$ $R A^{G}(x-s)$. We can have two cases: either $R A^{G}(x-\hat{s})>R A^{u}(x-r)$ or $R A^{G}(x-\hat{s})<$ $R A^{u}(x-r)$. In the first case, we have that $R A^{G}(x-s)>R A^{G}(x-\hat{s})>R A^{u}(x-r)$, so that $R A(x ; r, s)>R A(x ; r, \hat{s})$ follows from part (ii) of Proposition 5 . In the second case, we have that $R A^{G}(x-s)>R A^{u}(x-r)>R A^{G}(x-\hat{s})$. Thus, $R A(x ; r, s)>R A(x ; r, \hat{s})$ follows from the fact that, for any $x, r$ and $s, R A(x ; r, s)>R A^{u}(x-r)$ if and only if $R A^{G}(x-s)>R A^{u}(x-r)$.

\footnotetext{
${ }^{6}$ We replace the standard assumption that risk aversion is decreasing in absolute wealth, which is well supported by the experimental evidence (see, for example, Holt and Laury, 2002) with the assumption that, for what concerns the social component, risk aversion is decreasing in relative wealth. Indeed, if it holds true that individuals are less risk averse as they become richer, it is also plausible that individuals are less risk averse as they perceive to become richer, i.e., when they are further away from their social reference point.
} 
(ii) For the convexity of $G(\cdot)$ in the social losses, $R A^{G}(x-\hat{s})<R A^{u}(x-r)$. As it holds true that, for any $x, r$ and $s, R A(x ; r, s)>R A^{u}(x-r)$ if and only if $R A^{G}(x-s)>R A^{u}(x-r)$, we have that $R A(x ; r, \hat{s})<R A^{u}(x-r)$. Moreover, from the assumption that $R A^{G}(x-s)>$ $R A^{u}(x-r)$ it follows that $R A(x ; r, s)>R A^{u}(x-r)$. Thus $R A(x ; r, \hat{s})<R A(x ; r, s)$.

Consider prospects with social gains for which the decision maker is overall more risk averse than he would be for the same prospects in a private environment (i.e., $R A(x ; r, s)>R A^{u}(x-r)$ ), because his social risk aversion is higher than his private risk aversion (i.e., $R A^{G}(x-s)>$ $R A^{u}(x-r)$ ). Part (i) of Proposition 6 implies that, if we consider other prospects with social gains that are larger than these, because of the DARA assumption, the social risk aversion associated with the larger gains is lower than that associated with the smaller gains and, thus, also the overall risk aversion decreases.

The result of part (ii) of the proposition implies that the individual is less risk averse when facing social losses than he is when facing social gains, for which it holds true that the social risk aversion is higher than the private risk aversion. Indeed, in presence of any prospect with social losses, the decision maker is more risk lover than he would be for the same prospect in a private context (i.e., $R A(x ; r, s)<R A^{u}(x-r)$ ). The intuition is that, in a social environment, the decision maker may be willing to take more risks than he would do in absence of social comparison in order to shorten the distance from his social referent. Instead, what happens to risk attitudes in presence of social gains is ambiguous. Indeed, we can say in general that in presence of prospects with social gain the decision maker is risk averse. ${ }^{7}$ However, whether he is more or less risk averse than he would be for the same prospects in absence of social comparison ultimately depends on the relation between his private and his social risk aversion. If the decision maker dislikes more the risk associated with his standing relative to the social referent than relative to his private referent (i.e., $R A^{G}(x-s)>R A^{u}(x-r)$ ), than his overall risk aversion in presence of social gains is higher than his private risk aversion (i.e., $R A(x ; r, s)>R A^{u}(x-r)$ ). Consequently, his overall risk aversion in presence of social losses is lower than his overall risk aversion in presence of social gains.

Notice that there is no general relation between the risk attitudes in presence of social losses and the risk attitudes in presence of social gains, when the decision maker displays risk aversion in both situations. ${ }^{8}$ Moreover, as emphasized in part (i) of Proposition 6, if a decision maker in presence of some social gains displays a social risk aversion which is higher than his private risk aversion, there is no guarantee that this relation still holds when he faces larger gains, since social risk aversion decreases as gains grow larger. Hence, for different social gains situations, the same decision maker may display higher or lower risk aversion compared to the risk aversion he would display in a social losses situation.

Our theoretical results can be easily extended to decision makers characterized by a linear individual component $u(\cdot)$. For such individuals Proposition 6 applies as in the social gains domain it holds true that, for any $x, r$ and $s, R A^{G}(x-s)>R A^{u}(x-r)$ as $G(\cdot)$ is concave and $R A^{u}(x-r)=0$.

In the remaining sections of the paper we describe an experiment that investigates whether and how a variation in the social position of the agent, that is, a variation of $s$, affects his

\footnotetext{
${ }^{7}$ In our setting, the decision maker is risk averse in presence of social gains, because $G(\cdot)$ is concave in this domain, this is not always the case in presence of social losses. It can be shown that in the social losses domain the decision maker is overall risk averse, i.e., $R A(x ; r, s)>0$, if and only if $u^{\prime \prime}<-\gamma G^{\prime \prime}$.

${ }^{8}$ Obviously, if the decision maker displays risk loving behavior in the social losses domain, than it would be immediate to rank his risk attitudes in the two regions, as in the social gains domain he is always risk averse.
} 
attitude toward risk in lottery choice problems.

\section{The experiment}

We analyze the effect of social comparison on risk taking behavior by reproducing in the lab a workplace environment, where, after being paired with a co-worker, subjects perform an effort task, get a wage from this task and, afterwards, face a risky decision which can generate a bonus on top of their wage. The scenario we have in mind is a financial institution whereby risk takers perceive a pay which is given by a fixed part, the wage, and a variable part, the bonus, which depends on the success of their investment decisions.

Such a pay structure reflects the assumption that subjects evaluates possible outcomes of a risky decision (possible bonuses) as positive variations with respect to their individual reference point $r$. So far, we did not make any assumption about the nature of $r$; in the experiment, we assume that the subject's individual reference point coincides with his wage from the effort task. In order to make subjects perceive their individual reference point as compelling as possible, we assign it as a compensation for their effort. In addition, the presence of two possible wages will allow us to verify whether we induced $r$ appropriately, so that subjects actually evaluate bonuses as variations with respect to their wages.

We impose an individual reference point for two different reasons. On one hand, we believe that an intrinsic reference point (e.g., the status quo) exists and is an important determinant of individual decisions, both in private and social contexts. On the other hand, we want to isolate the effect of the social reference point, $s$; therefore, it is important to make the individual reference point as most explicit as possible in order to avoid that subjects implicitly form their own $r$, that we cannot control and that might interact with $s$. An explicit and well imposed individual reference point allows us to disentangle the effect of social comparison on risk taking behavior.

As expressed in the value function introduced in Section 2, we assume that, when facing a risky decision, an individual not only evaluates its possible outcomes as positive variations with respect to his wage (i.e., $r$ ), but he also compares his final earnings with the final earnings of his peer (i.e., $s$ ). In the experiment, when taking the investment decision which determines the bonus, subjects can compare their possible final payoffs (including the bonus) with the final payoff of their co-worker.

To induce a clear social reference point, we implement a payment scheme such that, in every pair, both workers get the fixed part of their final earnings (i.e., the wage), but only one of the two subjects (randomly determined) is paid the relative part of his final earnings (i.e., the bonus). Thus, subjects are aware that, if they receive the bonus, their colleague does not, so that their colleague's final earnings coincide with their colleague's wage. ${ }^{9}$ Hence, from the subject's perspective, his wage represents his individual reference point $r$, while the co-worker's wage represents his social reference point $s$. Obviously, a worker's individual reference point is also his co-worker's social reference point. Hence, allocating wages in a pair, we induce at the same time the individual and the social reference point for each of the two individuals.

Notice that the social reference point is fixed: it does not depend on the worker's investment decision nor on the chance move that determines the realization of the investment. As discussed in Section 2, our theory could accomodate a state-dependent $s$. We do believe that we could

\footnotetext{
${ }^{9}$ In principle, we could make one of the two workers completely inactive in the investment decision of the bonus task. However, on one side, the randomized payment of the bonus task is a fairer procedure, and, on the other side, it allows us not to lose observations.
} 
allow the social reference point to be state dependent also experimentally. However, a fixed social referent is more salient and makes social comparison easier, limiting the cognitive load imposed on subjects.

By manipulating wages allocation across pairs, we expose participants to different pairwise social comparison situations, characterized by the profile $(r, s)$. We study how risk attitudes vary depending on the social situation with a between subjects analysis: conditional on the wage pairs, for some subjects the bonus task displays social gains, for others social losses. ${ }^{10}$ Therefore, a subject can face either a downward comparison situation, when his final earnings are larger than his social reference point, or an upward comparison situation, when his final earnings are smaller than his social reference point. In particular, there are two possible wages, a low and a high one and every subject is assigned either wage with the same probability. We allocated wages so to have overall four possible profiles $(r, s)$. For no wage profile $(r, s)$ subjects can invert the (pairwise) social ranking with their investment decisions. ${ }^{11}$ Indeed, the payoff structure of the bonus task is such that if a worker has the low wage and the co-worker has the high wage, what the worker can get with the bonus is not enough to make him earn more than his co-worker. Obviously, if a worker has either the same wage as his co-worker or the highest wage in the pair, his final earnings including the bonus would be certainly larger than his co-worker's final earnings.

\subsection{The experimental design in detail}

The experiment consists of two parts. Subjects complete both parts, but they are paid only for one of them, which is randomly drawn by the computer at the end of the experiment (with independent draws); the probability that the first part is paid is $10 \% .{ }^{12}$ Payoffs are expressed in Experimental Currency Units (ECU), whereby 1 ECU corresponds to 1 euro. Paper-based instructions for each part are distributed separately. At the beginning of each part, after reading the instructions, participants answer some control questions (displayed on the screen). After the second part and before the payments, participants answer a computer-based questionnaire.

The first part of the experiment consists of a risk elicitation task, which we use to classify the participants' risk attitudes in absence of a social environment. In the second and main part of the experiment, we reproduce the workplace environment by pairing every subject with a co-worker. Each pair then undertakes an effort task (work task) that determines the workers' wages; afterwards, each worker faces a risky decision that can generate a bonus (bonus task). For the first risk elicitation task and the bonus task we adopt the same procedure, which is described below in detail for the first of the two tasks.

First part: The risk elicitation task. To elicit participants' risk preferences, we use a Multiple Price List (MPL) format (Holt and Laury, 2002; Laury and Holt, 2005). Subjects face a menu of ten choices between two lotteries (A and B) with two possible monetary outcomes each; lottery A pays either 2.00 ECU or 1.60 ECU, while lottery B pays either 3.85 ECU or 0.10

\footnotetext{
${ }^{10}$ As discussed in the previous section, in this paper we do not consider decision processes that involve mixed prospects.

${ }^{11}$ We agree that to revert the social ranking could be a driving force for risky behavior. For instance, decision makers could attribute high value to being the first and this would constitute a plausible incentive to choose a risky investment in the bonus task. However, our concern in this paper is to study how the relative position in the social ranking per se affects the risk attitudes of the decision maker.

${ }^{12}$ Not knowing which part will be considered for payment forces subjects to focus on every part as if it were the part actually paid.
} 
ECU. ${ }^{13}$ Hence, lottery A is "safer" than lottery B. The ten choices in the task differ only in the probability distribution over monetary outcomes, while the stakes of these outcomes are fixed across choices. In the first choice, the probability of the unfavourable outcome of both options is 1 (as in Laury and Holt, 2005) and it decreases by $10 \%$ in each of the subsequent choices, down to 0.1 in the tenth and last choice. Therefore, a rational decision maker would choose lottery $\mathrm{A}$ in the first choice, since the unfavourable outcome (occurring with probability 1) of lottery $\mathrm{A}$ is larger than the unfavourable outcome of lottery B. As the probability of the unfavourable outcome decreases enough, a decision maker should switch to the "riskier" lottery B.

For what concerns risk preferences, risk aversion is measured on the basis of the number of consecutive safe choices made by the subject. Outcomes are such that a risk neutral decision maker would choose option A for the first five decision rows and option B for the remaining five; a risk averse decision maker would choose option $\mathrm{A}$ for at least the first five rows, while a risk lover would choose option A for at most as many times.

We modify the MPL format, by making the components of the decision problems as visual as possible. Figure 1 shows the screenshot of the risk task.

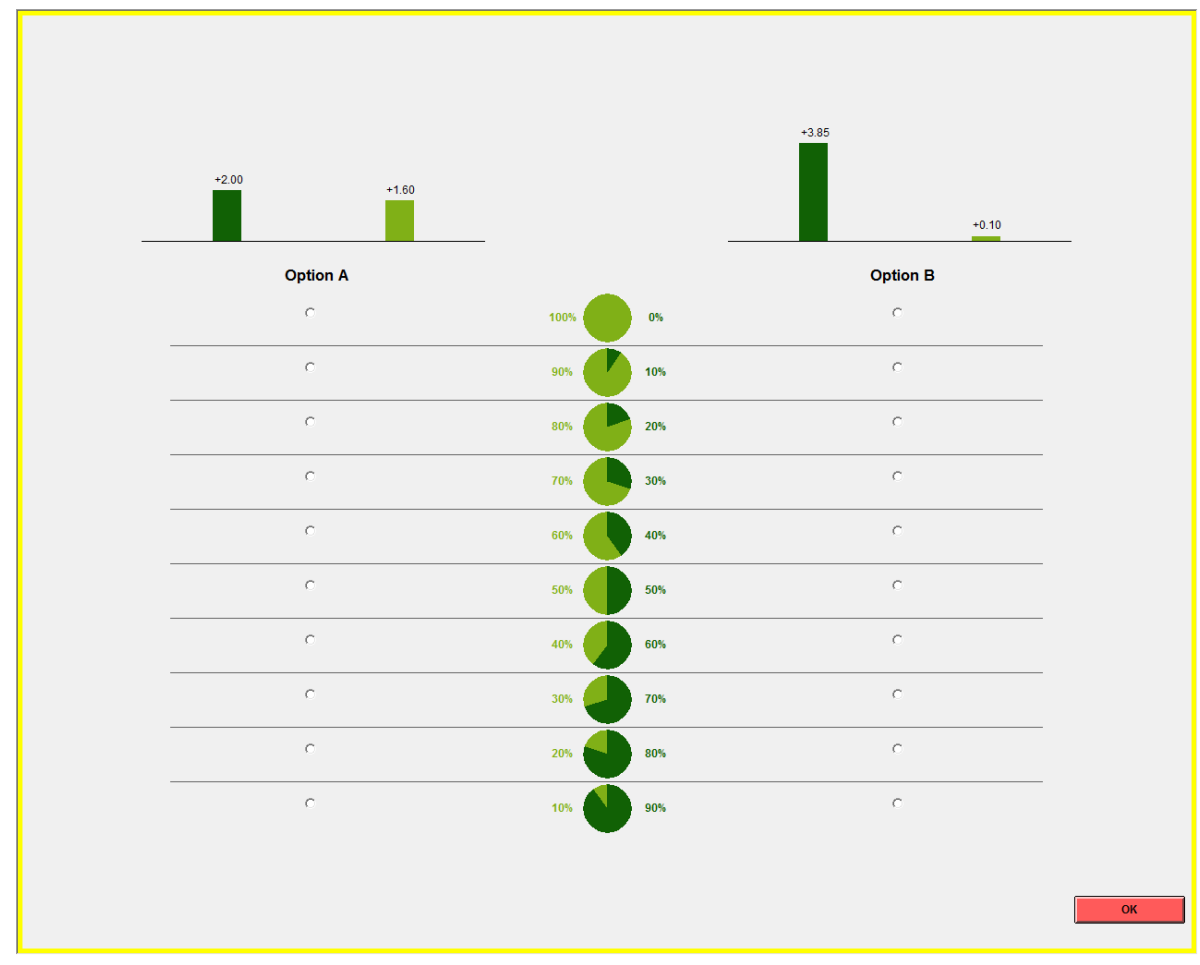

Figure 1: Risk elicitation task

The two options are displayed on the top of the screen and their possible outcomes are described by colored bars. The length of each bar reflects the amount of the monetary outcome and its color reflects whether the outcome is favorable (dark green) or unfavorable (light green). Right below these pictures there are the ten decision rows, whereby each row describes a choice. In each row, a pie chart represents the relative probabilities of the favorable and the unfavorable outcome of either option: the light green colored slice of the pie represents the probability of the favorable outcome and the dark green colored slice of the pie represents the probability of the unfavorable outcome. Relative probabilities are also indicated in numbers (in percentage terms).

\footnotetext{
${ }^{13}$ These are the same stakes as in Holt and Laury (2002).
} 
In every decision row participants have to choose between option A and option B. They can make the ten decisions in any order and they can change their decisions at any time before pressing the ok button at the bottom of the screen. Moreover, they can freely switch back and forth from one option to the other.

First part: The payment. At the end of the whole experiment, the computer determines for each subject whether the first or the second part is paid. If this first part is paid, the computer randomly draws one of the ten decision rows (for each subject independently), the lottery chosen by the subject is played and paid out. Thus, the subject gets the realized outcome of the chosen lottery for the decision row that has been drawn plus a participation fee of 2.50 euros.

Second part: The work task. After reading the instructions for the second part, subjects are randomly paired with a co-worker and offered a contract. We offer every participant one of two contracts, contract E and contract F. Both contracts pay the work task either 2 ECU or 10 ECU, depending on a computerized coin toss, which will be played after the work task is completed, and provided that the worker completes the task (otherwise he gets 0 ECU). The two contracts differ in the extent that one pays the high wage of 10 ECU when head is tossed (contract E) and the other when tail is tossed (contract F). At this stage, participants are only informed about their own contract: they are not aware of the contract assigned to the co-worker and they do not know which wage they will earn. In every session, we allocated contracts in such a way that half of the subjects are assigned the 10 ECU wage and half the 2 ECU wage (subjects receive this information in the instructions). Notice that this contract allocation scheme ensures a fair wage distribution across all participants in a session and a procedurally fair wage distribution across co-workers in every pair. ${ }^{14}$ The work task consists of two similar parts, each lasting a maximum of four minutes. If a subject does not complete either part, he gets 0 ECU. In each part, one has to write 20 combinations of two letters out of a given set of 10 letters (a, b, c, d, $\mathrm{e}, \mathrm{f}, \mathrm{g}, \mathrm{h}, \mathrm{i}, \mathrm{j}$, in the first part; $\mathrm{k}, \mathrm{l}, \mathrm{m}, \mathrm{n}, \mathrm{o}, \mathrm{p}, \mathrm{q}, \mathrm{r}, \mathrm{s}, \mathrm{t}$, in the second part). Participants cannot write in the same combination twice, and they cannot write in combinations already validated to their co-worker. If any of these two situations occurs, the participant receives an error message (two different error messages appear for the two specific situations) and has to write in another combination. This procedure creates a link between co-workers: by encountering each other during the work task (when they write in the same combinations) - or by knowing that there is the possibility that this happens - they get the perception of the existence of the other. In addition, when the work task is completed they are informed also about the wage realized by the co-worker. So, even if there is no competition between co-workers in the strict sense of a strategic interaction, we recreate a relation between them. ${ }^{15}$

After the work task, participants who completed both parts of this task are told the result of the coin toss ${ }^{16}$ their own wage and the co-worker's wage.

Second part: The bonus task. We used a MPL format also for the bonus task. The task is very similar to the risk task contained in the first part of the experiment, the only difference being the stakes and some additional information displayed on the screen in the bonus task.

\footnotetext{
${ }^{14}$ Obviously, exactly half of the subjects will actually get 10 ECU and half 2 ECU only when everybody in the session completes the task.

${ }^{15}$ Notice that a more competitive interaction would generate emotions with an impact on the bonus task that would be out of our control.

${ }^{16}$ There is a unique coin toss for all subjects in a session.
} 
Lottery A pays now either 4.00 ECU or 3.20 ECU, while lottery B pays either 7.70 ECU or 0.20 ECU. ${ }^{17}$ As in the first part of the experiment, lottery A is safer than lottery B, the first choice assigns probability 1 to the unfavorable outcome and a rational decision maker would prefer lottery $\mathrm{A}$ in the first choice. In the bonus tasks, the two lotteries are presented as projects that can generate additional earnings for the worker and outcomes are presented as positive variations with respect to the wage previously earned. On the top of the screen we recall both the worker's and the co-worker's previous wage.

Both workers face the bonus task, but the task will be paid out only to one of them. If this is the case, the subject will receive the realized bonus on top of his previous wage, while his co-worker will receive only his previous wage. Each worker in a pair is selected with equal probability at the end of the experiment; we call the selected worker the team leader. The fact that the identity of the leader is unknown during the bonus task induces both workers to focus on the investment decision as if they were the leader: the bonus task has indeed economic consequences for a subject only in case he is the leader. This procedure allows us to uniquely identify the social reference point as the co-worker's wage. For this reason, we made this mechanism very clear in the instructions and we insist on it in the control questions: if one is the team leader his choice in the bonus task becomes effective and the other worker gets only his wage. Our purpose is to make easier for subjects to compare their final payoff (which is outcome dependent) with the final payoff of their co-worker which is fixed at the co-worker's wage. ${ }^{18}$

Figure 2 shows the screenshot of the bonus task.

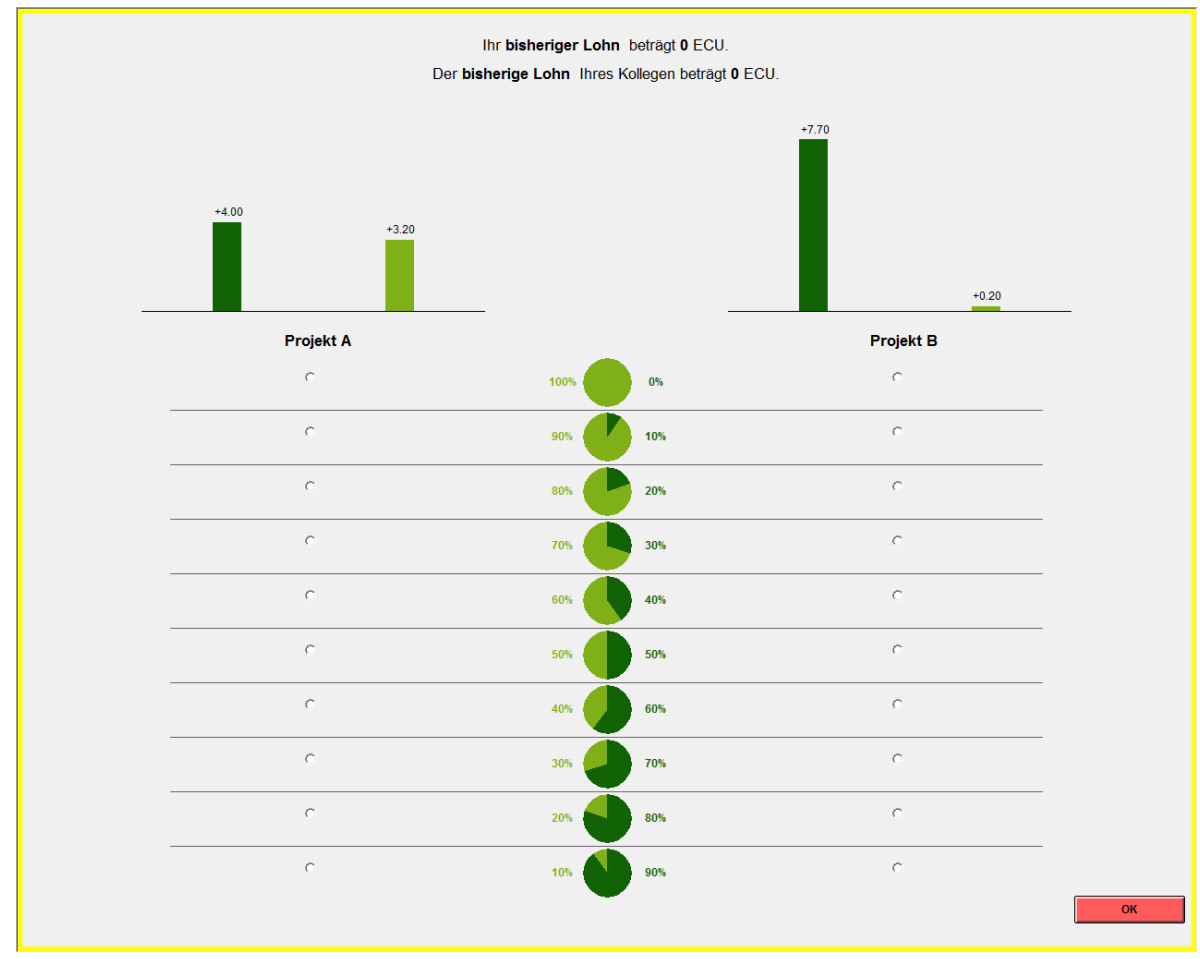

Figure 2: Bonus task

\footnotetext{
${ }^{17}$ There are the same stakes as in Laury and Holt (2005).

${ }^{18}$ Notice that in principle we could make the social reference point outcome-dependent (both theoretically and experimentally). We chose to fix the social reference point to make decision maker's life simpler and social comparison more stringent.
} 
Second part: The payment. If the second part is paid, one decision maker for each pair is drawn as the team leader. The leader gets the wage from the work task plus the realized bonus and the participation fee of 2.50 euros. To compute the bonus, we follow the same payment criterion as for the first part of the experiment: we pick one row for each team leader, we play the lottery out and we assign as a bonus the realized outcome of the lottery. Instead, the worker who has not been selected as a team leader gets his wage plus the participation fee of 2.50 euros.

\subsection{Hypotheses and treatments}

In this paper we focus on two research questions: Does social comparison affect risk attitudes? And, if this is the case, how do risk attitudes change across social situations?

To answer these questions, we focus on the link between risk attitudes and the four possible profiles of reference points that we induce in the experiment. Recall that the individual reference point $r$ is the subject's wage from the work task, $r \in\{2,10\}$, while the social reference point $s$ is the co-worker's wage from the effort task, $s \in\{2,10\}$. We divide subjects into four possible groups, whereby each group is identified by a certain realization of the wage profile $(r, s)$. We perform a between subjects analysis and compare risk attitudes of subjects belonging to different groups.

Notice that, given the lotteries offered as choices in the bonus task, it is not possible for a worker with wage 2 paired with a co-worker with wage 10 to have a final outcome larger than his co-worker's one, not even by winning the highest possible bonus. Therefore, for subjects in group $(2,10)$, the lotteries in the bonus task are prospects with social losses. Instead, for subjects in group $(2,2)$, the lotteries in the bonus task are prospects with social gains. Hence, by comparing the behavior of subjects in group $(2,10)$ with that of subjects in group $(2,2)$, we compare risk attitudes in a social losses condition with risk attitudes in a social gains condition. However, as our theoretical predictions about risk attitudes in the social gains domain are ambiguous, we consider two additional groups, i.e., group $(10,10)$ and group $(10,2)$. In these two groups the individual reference point is fixed and equal to 10, while the social reference point varies so to induce social gains that are larger in group $(10,2)$ than in group $(10,10)$.

To summarize, we identify four possible social conditions:

- $(2,10):$ prospects with social losses;

- $(2,2)$ : prospects with (small) social gains;

- $(10,10)$ : prospects with (small) social gains;

- $(10,2)$ : prospects with (large) social gains.

First of all, we will compare risk taking behavior across those groups that differ only in the social reference point, while $r$ is constant, in order to verify whether we can reject the null hypothesis that relative status does not influence risk attitudes, that is:

H0 (Social comparison does not matter.) Risk attitudes do not differ neither across subjects facing social losses (group $(2,10)$ ) and small social gains (group $(2,2)$ ) nor across subjects facing small social gains (group $(10,10)$ ) and large social gains (group $(10,2)$ ).

Notice that rejecting this hypothesis would provide support to the assumption that the social component of the value function $G(\cdot)$ is not linear (see Proposition 4). 
Secondly, we will investigate how social comparison influences risk attitudes. In order to do so, we will preliminarily test whether risk attitudes do not differ across groups $(2,2)$ and $(10,10)$. Indeed, according to our theoretical framework, subjects in group $(2,2)$ and in group $(10,10)$ should behave in the same way, given that in the bonus task they face the same variation with respect to the social reference point $(x-s)$ and the same variation with respect to the individual reference point $(x-r)$. We can state this hypothesis as follows:

H1 (Reference dependence.) Subjects in group $(2,2)$ behave as subjects in group $(10,10)$.

The next two experimental hypotheses are related to the way in which risk attitudes change across social conditions. In our theoretical framework, we discussed the behavioral implications of a value function that displays prospect theory features in its social component $G(\cdot)$ (see Proposition 6). Hypothesis $\mathrm{H} 2$ below relates to part (i) of Proposition 6, while $\mathrm{H} 3$ relates to part (ii) of the same proposition.

H2 (Risk aversion is decreasing in social gains.) Subjects in groups $(2,2)$ and $(10,10)$ are more risk averse than subjects in group $(10,2)$.

This prediction is derived from the assumption that the social component of the value function is decreasing in the social gains and that, for the group with smaller social gains (i.e., $(2,2)$ ), the social risk aversion is higher than the risk aversion of the private component. Notice that, given our experimental setting, these two assumptions are not directly testable. However, as our theoretical model accounts for different risk attitudes in the social gains domain, we want to verify whether we do indeed observe different risk attitudes depending on how far one's outcome is from the social reference point. ${ }^{19}$

In accordance with part (ii) of Proposition 6, hypothesis H3 below predicts that individuals display more risk aversion in presence of small social gains than in presence of social losses.

H3 (Risk aversion in social gains is larger than risk aversion in social losses.) Subjects in groups $(2,2)$ and $(10,10)$ are more risk averse than subjects in group $(2,10)$.

Hypothesis $\mathrm{H} 3$ is silent on the comparison between risk attitudes in group $(2,10)$ and group $(10,2)$. Indeed, we learned from our theoretical analysis that the relation between the risk attitudes of groups with social losses and of groups with social gains depends on whether the social component of the value function associated with these social gains displays more risk aversion than the private component. As social risk aversion is decreasing in social gains it is more likely that this condition is satisfied for small than for large social gains. If this is the case, we have a clear ranking between the risk attitudes in the two regions.

To summarize, if we consider social gains for which it holds true that the social risk aversion is higher than the private risk aversion, we can compare the risk attitudes in presence of such gains both with the risk attitudes in presence of larger social gains (as in hypothesis H2) and with the risk attitudes in presence of (any) social losses (as in hypothesis H3).

\footnotetext{
${ }^{19}$ For what concerns environments with social losses, our theoretical analysis tells us that the overall risk aversion is increasing in the social referent $s$, independently of the relation between the private and the social risk aversion (provided that the $G(\cdot)$ is CARA or DARA). As this prediction is unambiguous, we did not consider particularly interesting to investigate further on such comparative statics and, therefore, we took only one wage profile in this domain, i.e., $(2,10)$.
} 


\subsection{Participants and Procedures}

We ran the experimental sessions in March and in July 2013 at the lab of the Max Planck Institute of Economics in Jena. We recruited 436 participants from various disciplines at the local university using the ORSEE software (Greiner, 2004). We ran 14 sessions in total. The average age of participants was approximately 24. The experiment was programmed and conducted with the software Z-tree (Fischbacher, 2007) and lasted approximately one hour. The average earnings in the experiment have been approximately 10.20 euros (including a 2.50 euros participation fee). Upon arrival at the laboratory, subjects were randomly assigned to one of the computer terminals. Each computer terminal is in a cubicle that does not allow communication or visual interaction among the participants. Participants were given time to privately read the instructions for each part of the experiment and were allowed to ask for clarifications. In order to check the understanding of instructions subjects were asked to answer some control questions (after reading the instructions of each part). Each part of the experiment started after all subjects correctly respond to the control questions. At the end of the experiment subjects were paid in cash, after the completion of the questionnaire. Privacy was guaranteed during the payment phase.

\section{Experimental Results}

Before going into the discussion of our experimental results, we present a preliminary analysis of the risk preferences of the participants as elicited in the first part of the experiment.

The first thing to notice is that the visual application of the risk elicitation task by Holt and Laury (2002) and Laury and Holt (2005) is very efficient in producing consistent results. In particular, we only focus on subjects who do not start from the dominated lottery in the first row and do not switch multiple times in either task. Overall, 424 out of 436 subjects display none of such inconsistencies. The largest number of mistakes is made in the first task, whereby 11 subjects make multiple switches between the lotteries, and one of them also starts from the dominated lottery in the first row. In the bonus task only 6 subjects switch multiple times $(5$ of which had also inconsistencies in the first task), while nobody starts from the dominated lottery; so that overall only 12 subjects display one or more of these inconsistencies. We drop these 12 subjects from the sample. This result is particularly interesting if one considers for example that Laury and Holt (2005) have 44 subjects out of 157 who present multiple switches.

Moreover, there are 4 subjects who did not complete the work task, and for this reason got a zero wage. We drop these subjects and also their co-workers from the sample, as we believe that different incentives and mechanisms of social comparison may operate in case a failure of one of the members of the team gives rise to wage inequality.

Therefore we drop from the sample 19 subjects overall. ${ }^{20}$

We focus only on the remaining 417 subjects who start from the dominant lottery (lottery A) in the first row and switch to the riskier one only once. In order to evaluate the risk attitudes of these subjects we can hence use the number of (continuous) safe choices in either of the two risk elicitation tasks as a measure of their degree of risk aversion. As discussed in Section 3.1, in each task a risk neutral subject would switch exactly at the fifth row, a risk averse subject would switch after the fifth row, and a risk lover would switch before it.

\footnotetext{
${ }^{20}$ This is because one of the subjects with zero wage also belongs to the group of subjects with inconsistencies in the behavior of the first risk task.
} 
Table 1 provides a classification of the subjects according to the risk type that is implied from the individual risk elicitation task. We are going to use this information in order to test $\mathbf{H 2}$

Table 1: Individual risk attitudes

\begin{tabular}{lrr}
\hline Risk Type & Freq. & Percent \\
\hline risk averse & 262 & 62.83 \\
risk neutral & 85 & 20.38 \\
risk lover & 70 & 16.79 \\
\hline Total & 417 & 100.00 \\
\hline
\end{tabular}

and $\mathbf{H 3}$ which are related to theoretical results derived from the assumption that individuals are risk averse in an environment without social comparison. Moreover, the individual risk elicitation task allows us to control for the individual risk attitudes when we analyze the effect that social comparison has on the behavior of subjects in risky choices. This is particularly helpful because we perform a between subjects analysis of the effect of social comparison; by introducing a measure of individual risk aversion we can isolate the social component in a more precise way. However, we do not compare directly the measures of risk attitudes derived in the first and second risk tasks for several reasons. First of all, the lotteries used in the two tasks are different and, therefore, the two measures are not directly comparable. Moreover, the framing of the problem is different: in the first case the risk task is introduced as a single set of choices made in absence of a social context; the bonus task is instead part of a longer task, which includes also the work task, and moreover it is characterized by the presence of a co-worker and more information on the screen itself. Finally, the individual risk task always comes first, as we do not randomize the order of the two parts of the experiment.

Let us introduce our analysis by showing some preliminary descriptive statistics of our measure in the four different groups, defined by the pair $(r, s)$. Table 2 shows for each group the average number of continuous safe choices in the bonus task, its standard error, its $95 \%$ confidence interval and the number of subjects that belong to the group itself.

Notice that the regions where both subjects in the pair have received the same wage have a higher average number of safe choices; the variations between the regions may not seem relevant, however we must notice that the MPL format has a tendency to induce a large concentration of switches around 5 or $6 .^{21}$

Table 2: Descriptive statistics

\begin{tabular}{lrrcr}
\hline Group & Mean & Std. Err. & $95 \%$ Conf. Int. & Obs. \\
\hline$(2,2)$ & 6.14 & .15 & {$[5.85,6.43]$} & 101 \\
$(2,10)$ & 5.90 & .15 & {$[5.60,6.19]$} & 107 \\
$(10,2)$ & 5.96 & .15 & {$[5.66,6.26]$} & 106 \\
$(10,10)$ & 6.26 & .14 & {$[5.98,6.55]$} & 103 \\
\hline
\end{tabular}

We perform a between subjects analysis to study whether and how the presence of social comparison affects risk attitudes. We conduct such analysis using OLS. The regressions we run for the main analysis follow the general model of equation (6), where the dependent variable

\footnotetext{
${ }^{21}$ See Harrison et al. (2005) for a discussion on the MPL format.
} 
$S C B$ is the number of consecutive safe choices in the bonus task, $X$ stands for the relevant regressors for the analysis, and $Z$ contains the additional individual controls. We describe more in detail the variables of interest in the list below.

$$
S C B_{i}=\alpha+\beta X_{i}+\gamma Z_{i}+\varepsilon_{i}
$$

Dependent variable $(S C B)$. It is the number of consecutive safe choices in the bonus task. The higher is $S C B$, the higher is the risk aversion of subjects. It can take values from 1 to 10 .

Regressors of interest $(X)$. Depending on the specification, we use the following regressors (summary statistics are included in Table 13 contained in the Appendix):

- $S C I$ : it is the number of consecutive safe choices in the risk elicitation task; as $S C B$, it can take values from 1 to 10 ;

- wage: it is the wage that the subject receives for its work task; it can be either 2 or 10;

- $D(2,10)$ : it is a dummy that identifies subjects who belong to the group $(2,10)$;

- $D(10,2)$ : it is a dummy that identifies subjects who belong to the group $(10,2)$;

- envy: it is a subjective emotional evaluation derived by question (12) from the final questionnaire; subjects are asked to state how much envy (among other emotions) describes their feeling in the bonus task, where the possible answers go from "Not at all" (coded as 1) to "Perfectly" (coded as 5).

Other individual controls $(Z)$. We include in our regressions also individual controls that come from the final questionnaire. In particular, we focus on age, gender (where 0 is female) and height (expressed in $\mathrm{cm}$ ). ${ }^{22}$ The sample characteristics of these variables are summarized in Table 13, contained in the Appendix; in the same table we also report subsample characteristics across the four groups defined by the pairs $(r, s)$, from which it is possible to notice that the sample is quite homogeneous.

We focus on three specifications. First of all, we split the sample in two subsamples: subjects who received wage 2 and subjects who received wage 10 . On each subsample, we regress the dependent variable $S C B$ over the individual measure of risk attitudes $(S C I)$ and the relevant dummy for the social comparison (i.e., $D(2,10)$ for the group with wage 2 and $D(10,2)$ for the group with wage 10) in order to have an initial look at the effects that social comparison has on subjects' risk attitudes. We do this twice for each group, both with and without the individual controls; results are included in Table 3, columns (1)-(4).

Then we focus on the group of workers who have the same wage as their co-worker. For this subset we run two regressions, one with individual controls and one without them, that can be found in Table 4. In each regression we investigate, by including the wage as a regressor, whether the behavior of subjects who belong to the group $(2,2)$ can be distinguished from the behavior of subjects in the group $(10,10)$. Notice that for subjects in these two groups the choices performed in the bonus task display the same differences $(x-s)$ and $(x-r)$.

\footnotetext{
${ }^{22}$ In the questionnaire, we also asked subjects to report their weekly budget. However, since we inferred from their unplausible answers that they did not understand the question, we do not consider this variable as a meaningful individual control.
} 
Table 3: Analysis by wage group

\begin{tabular}{|c|c|c|c|c|c|c|}
\hline \multirow[b]{2}{*}{ SCB } & \multicolumn{2}{|c|}{ wage $=2$} & \multicolumn{2}{|c|}{ wage $=10$} & \multicolumn{2}{|c|}{ all subjects } \\
\hline & $(1)$ & $(2)$ & $(3)$ & (4) & $(5)$ & (6) \\
\hline \multirow[t]{2}{*}{ SCI } & 0.600 & 0.601 & 0.479 & 0.484 & 0.534 & 0.537 \\
\hline & $(11.38)^{* * *}$ & $(11.23)^{* * *}$ & $(9.29)^{* * *}$ & $(9.27)^{* * *}$ & $(14.46)^{* * *}$ & $(14.45)^{* * *}$ \\
\hline \multirow[t]{2}{*}{$\mathrm{D}(2,10)$} & -0.268 & -0.265 & & & -0.343 & -0.340 \\
\hline & $(1.61)$ & $(1.57)$ & & & $(2.32)^{* *}$ & $(2.28)^{* *}$ \\
\hline \multirow[t]{2}{*}{$\mathrm{D}(10,2)$} & & & -0.472 & -0.456 & -0.415 & -0.413 \\
\hline & & & $(2.65)^{* * *}$ & $(2.52)^{* *}$ & $(2.78)^{* * *}$ & $(2.76)^{* * *}$ \\
\hline \multirow[t]{2}{*}{ age } & & -0.009 & & -0.000 & & 0.001 \\
\hline & & $(0.36)$ & & $(0.02)$ & & $(0.08)$ \\
\hline \multirow[t]{2}{*}{ gender } & & 0.060 & & -0.127 & & -0.037 \\
\hline & & $(0.26)$ & & $(0.48)$ & & $(0.21)$ \\
\hline \multirow[t]{2}{*}{ height } & & 0.000 & & 0.008 & & 0.005 \\
\hline & & $(0.01)$ & & $(0.66)$ & & $(0.61)$ \\
\hline \multirow[t]{2}{*}{ Constant } & 2.508 & 2.654 & 3.392 & 2.016 & 2.988 & 2.055 \\
\hline & $(7.37)^{* * *}$ & $(1.12)$ & $(10.16)^{* * *}$ & $(0.82)$ & $(12.53)^{* * *}$ & $(1.22)$ \\
\hline$R^{2}$ & 0.39 & 0.39 & 0.30 & 0.31 & 0.34 & 0.34 \\
\hline$N$ & 208 & 208 & 209 & 209 & 417 & 417 \\
\hline
\end{tabular}

We see that subjects with a wage equal to their co-worker's wage are not distinguishable on the basis of their level of wage. This provides evidence in support of $\mathbf{H 1}$, as indeed the behavior of subjects in group $(2,2)$ is not distiguishable from the behavior of subjects in group $(10,10)$.

We can therefore aggregate subjects with a low and a high wage in the same regressions to verify whether and how the behavior of subjects with a higher $(D(10,2)=1)$ or lower $(D(2,10)=1)$ wage (with respect to their co-worker's one) differs compared with the behavior of subjects who start the bonus task from the same wage level. Results are displayed in columns (5) and (6) of Table 3.

Furthermore, we can notice that in every regression there is a strong correlation between social risk attitudes and individual risk attitudes: the effect of $S C I$ on the number of safe choices in the bonus task is positive and strongly significant everywhere. Moreover, the other individual characteristics that we introduce do not have a significant effect. ${ }^{23}$

Now we analyze in detail what the experimental data can tell on $\mathbf{H 0}, \mathbf{H} \mathbf{2}$ and $\mathbf{H 3 .}$

\subsection{Social comparison matters}

We want to verify whether we can reject $\mathbf{H 0}$, by checking if risk attitudes are indeed influenced by the social condition in which the subject found himself when choosing among risky lotteries.

To do so, we first look at the effects of the social condition on subjects with wage equal to 2 and on subjects with wage equal to 10 separately.

\footnotetext{
${ }^{23}$ Notice that these characteristics do not have a significant impact on $S C I$. This may be justified by the fact that the sample is homogeneous, as it is mostly formed by undergraduate students with a similar individual background.
} 
Table 4: Wage equal to co-worker's wage.

\begin{tabular}{|c|c|c|}
\hline \multirow[b]{2}{*}{ SCB } & \multicolumn{2}{|c|}{ wage $=$ co-worker's wage } \\
\hline & (1) & $(2)$ \\
\hline \multirow[t]{2}{*}{$\mathrm{SCI}$} & 0.579 & 0.569 \\
\hline & $(11.58)^{* * *}$ & $(11.22)^{* * *}$ \\
\hline \multirow[t]{2}{*}{ wage } & 0.020 & 0.026 \\
\hline & $(0.98)$ & $(1.23)$ \\
\hline \multirow[t]{2}{*}{ age } & & -0.015 \\
\hline & & $(0.58)$ \\
\hline \multirow[t]{2}{*}{ gender } & & -0.037 \\
\hline & & $(0.16)$ \\
\hline \multirow[t]{2}{*}{ height } & & -0.012 \\
\hline & & $(0.92)$ \\
\hline \multirow[t]{2}{*}{ Constant } & 2.596 & 5.044 \\
\hline & $(7.72)^{* * *}$ & $(2.02)^{* *}$ \\
\hline$R^{2}$ & 0.40 & 0.41 \\
\hline$N$ & 204 & 204 \\
\hline
\end{tabular}

From the first two columns of Table 3 , we can observe that given a wage equal to 2 , there is a negative effect of the co-worker's wage $s$ on risk aversion, as the coefficient of the dummy $D(2,10)$ is negative; however, such effect is not significant, when we look at the subsample of workers with a low wage.

Within the group of subjects with wage equal to 10, there is a positive effect of the co-worker's wage $s$ on risk aversion, and such effect is significant.

Alternatively, we can state these results as follows:

- Subjects in group $(2,10)$ are on average less risk averse than subjects in group $(2,2)$, but the difference is not significant.

- Subjects in group $(10,2)$ are on average significantly less risk averse than subjects in group $(10,10)$.

These two results imply that for a given wage, risk attitudes vary with the wage of the co-worker. As we fix $r$, it must be the case that the curvature of the social component $G(\cdot)$ depends on $s$. This implies that our social component $G(\cdot)$ cannot be linear (see Proposition 3 ); therefore, we can reject the null hypothesis $(\mathbf{H 0})$.

As we noticed, the effect is stronger and more significant for $D(10,2)$ than for $D(2,10)$. We will discuss in Section 5.1 how this may be due to subjects with lower wage being more prone to experience envy.

As we observed from Table 4 , subjects in groups $(2,2)$ and $(10,10)$ cannot be distinguished according to their wage; hence, we pool them together and we perform the same analysis on the whole sample of subjects. The results, shown in columns (5)-(6) of Table 3, confirm the same pattern, with the addition that the coefficient of the dummy $D(2,10)$ is now significant as well.

We can then conclude that social comparison does indeed affect the risk attitudes of individuals. 
We should also consider whether the co-worker's wage is really what subjects consider as social reference point. Theoretically, in a keeping up with the Joneses spirit, subjects could also take as reference point (an estimate of) the average final outcome of the population. Subjects in groups $(10,2)$ and $(10,10)$ are in the best possible initial condition when facing the bonus task. Hence, even if they may find it difficult to formulate a correct estimate of the population average, given the available information, they may easily expect to get a final outcome which is above the average final outcome of the population. ${ }^{24}$ Given that they share the same $r$, the same $x$ and the awareness of being above the average, this can be rationalized only by consideration of the fact that their social reference point differs.

Our experimental evidence is also inconsistent with a keeping up with the winners phenomenon, according to which subjects take as reference point the highest possible earnings in the population. ${ }^{25}$ In our experimental setting the winners would be subjects who get a wage of 10 and who are selected as project leaders, getting a final outcome certainly larger than 10 . Subjects with a low wage, i.e., subjects of groups $(2,2)$ and $(2,10)$, share the same $r$, the same $x$ and the same disadvantageous social condition compared to the winners. Still, the risk taking behavior in the bonus task does differ across these two groups.

Taken together, these observations provide support to the assumption that what subjects consider as social reference point in our experimental setting is indeed the co-worker's wage.

\subsection{Risk-taking behavior across social conditions}

To better analyze the effect of social comparison on the risk-taking behavior displayed in the bonus task, we distinguish subjects on the basis of the risk attitude they displayed in absence of a social environment (i.e., in the risk elicitation task of the first part). ${ }^{26}$ In this section we replicate the above analysis that we proposed above for the subsample of subjects who displayed risk aversion or risk neutrality in the risk elicitation task of the first part. Notice that this subsample constitutes the large majority of subjects (347 out of 417). Similarly to Table 2 , Table 5 provides the average number of consecutive safe choices across groups within this subsample of subjects. In Section 5, we will shortly discuss the experimental results regarding the small subsample of risk lover subjects.

The reason for splitting the sample is that the implications of our theoretical model depend on the curvature of the individual component of the value function. In the theoretical section, we assumed that individuals are risk averse in absence of a social context (i.e., $u(\cdot)$ is concave) and in presence of individual gains as in prospect theory, and we studied the implications of social comparison under this assumption. ${ }^{27}$ We discussed also that such implications would not change in case $u(\cdot)$ was linear. Instead, if we assumed convexity of $u(\cdot)$, it would not be possible to say something conclusive about the impact of social comparison on risk taking behavior.

If we analyze the results of Table 6 , we can notice from columns (1)-(2) that the dummy $D(2,10)$, that identifies the group of subjects in a social losses condition, has a significant and negative effect on the number of safe choices made in the bonus task. As confirmed by Table 7 , we can pool together groups $(2,2)$ and $(10,10)$, i.e., subjects who have the same wage as their co-worker. If we consider columns (5)-(6) of Table 6 , we notice that the effect of the dummy

\footnotetext{
${ }^{24}$ Notice that there is no reason to expect that the subjective assessment of the average final outcome as formulated by subjects in group $(10,2)$ would differ from the one by subjects in group $(10,10)$.

${ }^{25}$ This phenomenon is well supported, for example, by the experimental evidence of Fafchamps et al. (2013).

${ }^{26}$ Essentially, we take $S C I$ as a proxy for private risk aversion, i.e., $R A^{u}$.

${ }^{27}$ The assumption that most of individuals are risk averse finds empirical support not only in our data but also in many other empirical studies. See, for example, Holt and Laury (2002).
} 
Table 5: Risk averse: Descriptive statistics

\begin{tabular}{lrrcr}
\hline Group & Mean & Std. Err. & $95 \%$ Conf. Int. & Obs. \\
\hline$(2,2)$ & 6.33 & .15 & {$[6.04,6.62]$} & 88 \\
$(2,10)$ & 6.15 & .15 & {$[5.84,6.45]$} & 88 \\
$(10,2)$ & 6.22 & .16 & {$[5.89,6.54]$} & 88 \\
$(10,10)$ & 6.59 & .15 & {$[6.30,6.88]$} & 83 \\
\hline
\end{tabular}

Table 6: Risk averse: Analysis divided by wage groups

\begin{tabular}{|c|c|c|c|c|c|c|}
\hline \multirow[b]{2}{*}{$\mathrm{SCB}$} & \multicolumn{2}{|c|}{ wage $=2$} & \multicolumn{2}{|c|}{ wage $=10$} & \multicolumn{2}{|c|}{ all subjects } \\
\hline & (1) & $(2)$ & $(3)$ & (4) & $(5)$ & (6) \\
\hline \multirow[t]{2}{*}{ SCI } & 0.697 & 0.697 & 0.479 & 0.486 & 0.585 & 0.587 \\
\hline & $(10.23)^{* * *}$ & $(10.16)^{* * *}$ & $(6.31)^{* * *}$ & $(6.33)^{* * *}$ & $(11.41)^{* * *}$ & $(11.40)^{* * *}$ \\
\hline \multirow[t]{2}{*}{$\mathrm{D}(2,10)$} & -0.285 & -0.295 & & & -0.353 & -0.353 \\
\hline & $(1.69)^{*}$ & $(1.73)^{*}$ & & & $(2.21)^{* *}$ & $(2.20)^{* *}$ \\
\hline \multirow[t]{2}{*}{$\mathrm{D}(10,2)$} & & & -0.516 & -0.500 & -0.458 & -0.459 \\
\hline & & & $(2.57)^{* *}$ & $(2.47)^{* *}$ & $(2.84)^{* * *}$ & $(2.84)^{* * *}$ \\
\hline \multirow[t]{2}{*}{ age } & & 0.023 & & 0.005 & & 0.014 \\
\hline & & $(0.91)$ & & $(0.17)$ & & $(0.75)$ \\
\hline \multirow[t]{2}{*}{ genere } & & 0.112 & & 0.023 & & 0.026 \\
\hline & & $(0.50)$ & & $(0.08)$ & & $(0.14)$ \\
\hline \multirow[t]{2}{*}{ height } & & -0.005 & & 0.014 & & 0.005 \\
\hline & & $(0.47)$ & & $(0.98)$ & & $(0.56)$ \\
\hline \multirow[t]{2}{*}{ Constant } & 1.839 & 2.150 & 3.435 & 0.862 & 2.646 & 1.398 \\
\hline & $(4.04)^{* * *}$ & $(0.94)$ & $(6.60)^{* * *}$ & $(0.31)$ & $(7.63)^{* * *}$ & $(0.78)$ \\
\hline$R^{2}$ & 0.38 & 0.39 & 0.21 & 0.21 & 0.28 & 0.28 \\
\hline$N$ & 176 & 176 & 171 & 171 & 347 & 347 \\
\hline
\end{tabular}


Table 7: Risk averse: Wage equal to co-worker's wage

\begin{tabular}{|c|c|c|}
\hline \multirow[b]{2}{*}{ SCB } & \multicolumn{2}{|c|}{ wage $=$ co-worker's wage } \\
\hline & (1) & $(2)$ \\
\hline \multirow[t]{2}{*}{$\mathrm{SCI}$} & 0.643 & 0.639 \\
\hline & $(9.15)^{* * *}$ & $(8.98)^{* * *}$ \\
\hline \multirow[t]{2}{*}{ wage } & 0.021 & 0.024 \\
\hline & $(0.98)$ & $(1.12)$ \\
\hline \multirow[t]{2}{*}{ age } & & -0.014 \\
\hline & & $(0.49)$ \\
\hline \multirow[t]{2}{*}{ gender } & & -0.027 \\
\hline & & $(0.11)$ \\
\hline \multirow[t]{2}{*}{ height } & & -0.007 \\
\hline & & $(0.53)$ \\
\hline \multirow[t]{2}{*}{ Constant } & 2.148 & 3.749 \\
\hline & $(4.53)^{* * *}$ & $(1.36)$ \\
\hline$R^{2}$ & 0.34 & 0.34 \\
\hline$N$ & 171 & 171 \\
\hline
\end{tabular}

$D(2,10)$ is even larger and more significant. Similarly, columns (3)-(6) show that also the dummy $D(10,2)$, which identifies the subjects in a context of large social gains, has a negative effect on the number of safe choices made in the bonus task. Aggregating all this information, we can conclude that subjects display a lower degree of risk aversion in presence of large social gains (group $(10,2)$ ) than they do when facing small social gains (groups $(2,2)$ and $(10,10)$ ), as predicted by H2. Moreover, we find that subjects display a lower degree of risk aversion in presence of social losses (group $(2,10)$ ) than they do when facing small social gains (groups $(2,2)$ and $(10,10))$, as predicted by $\mathbf{H 3}$.

We can interpret these results as follows. Subjects in group $(2,10)$ take more risks compared to subjects in groups $(2,2)$ and $(10,10)$ because they may want to reduce the social distance from their peer. In addition, subjects in group $(10,2)$ take more risks than subjects in groups $(2,2)$ and $(10,10)$ because of a relative wealth effect. Indeed, subjects who are far above the peer's outcome feel relatively much richer compared to subjects who are slightly above it and, thus, choose risky situations more easily. As we can observe from Tables 2 and 5, we do not find any significant difference in risk taking behavior between subjects in group $(2,10)$ and subjects in group $(10,2)$.

\section{$5 \quad$ Further analysis}

\section{$5.1 \quad$ Envy}

We showed in Section 4 that upward and downward social comparison fosters risk taking behavior. We also found that the effect of the dummy $D(10,2)$ is larger and more significant than the effect of the dummy $D(2,10)$. A plausible behavioral explanation of this phenomenon is that the social losses condition may trigger different and conflicting emotions. On the one hand, 
disadvantaged subjects may be willing to take more risks in order to catch up with their peers; on the other hand, they may be willing to choose the safer option because they anticipate the envy they would feel in case the bad outcome occurs and they fall far below their peer's status. Using the information contained in our final questionnaire, we can investigate whether the second relation appears to be at work and how. First of all, it has to be said that a propension to envious feelings is triggered by a specific relative position in the social ranking. Table 8 provides the descriptive statistics of our measure of envy: we can observe that on average envy is higher for subjects in group $(2,10)$ than for subjects belonging to other groups. ${ }^{28}$

Table 8: Envy: Descriptive statistics

\begin{tabular}{lrrcr}
\hline Group & Mean & Std. Err. & $95 \%$ Conf. Int. & Obs. \\
\hline$(2,2)$ & 1.85 & .10 & {$[1.65,2.05]$} & 101 \\
$(2,10)$ & 2.61 & .12 & {$[2.37,2.84]$} & 107 \\
$(10,2)$ & 1.54 & .08 & {$[1.38,1.69]$} & 106 \\
$(10,10)$ & 1.81 & .11 & {$[1.59,2.02]$} & 103 \\
\hline
\end{tabular}

Using the data from the experiment, we check whether the relation between envy and risk attitudes in a social context occurs in our data.

Table 9: Envy: Analysis by wage group

\begin{tabular}{|c|c|c|c|c|c|c|}
\hline \multirow[b]{2}{*}{ SCB } & \multicolumn{2}{|c|}{ wage $=2$} & \multicolumn{2}{|c|}{ wage $=10$} & \multicolumn{2}{|c|}{ all subjects } \\
\hline & (1) & $(2)$ & $(3)$ & (4) & $(5)$ & (6) \\
\hline \multirow[t]{2}{*}{ SCI } & 0.590 & 0.591 & 0.478 & 0.483 & 0.529 & 0.532 \\
\hline & $(11.16)^{* * *}$ & $(11.01)^{* * *}$ & $(9.23)^{* * *}$ & $(9.21)^{* * *}$ & $(14.28)^{* * *}$ & $(14.29)^{* * *}$ \\
\hline \multirow[t]{2}{*}{$\mathrm{D}(2,10)$} & -0.356 & -0.358 & & & -0.407 & -0.405 \\
\hline & $(2.05)^{* *}$ & $(2.01)^{* *}$ & & & $(2.63)^{* * *}$ & $(2.60)^{* * *}$ \\
\hline \multirow[t]{2}{*}{$\mathrm{D}(10,2)$} & & & -0.464 & -0.447 & -0.389 & -0.387 \\
\hline & & & $(2.57)^{* *}$ & $(2.44)^{* *}$ & $(2.59)^{* * *}$ & $(2.57)^{* *}$ \\
\hline \multirow[t]{2}{*}{ envy } & 0.118 & 0.118 & 0.026 & 0.033 & 0.082 & 0.084 \\
\hline & $(1.61)$ & $(1.58)$ & $(0.28)$ & $(0.35)$ & $(1.41)$ & $(1.43)$ \\
\hline \multirow[t]{2}{*}{ age } & & -0.004 & & -0.001 & & 0.003 \\
\hline & & $(0.17)$ & & $(0.02)$ & & $(0.16)$ \\
\hline \multirow[t]{2}{*}{ gender } & & 0.085 & & -0.130 & & -0.030 \\
\hline & & $(0.37)$ & & $(0.49)$ & & $(0.17)$ \\
\hline \multirow[t]{2}{*}{ height } & & 0.001 & & 0.008 & & 0.006 \\
\hline & & $(0.08)$ & & $(0.66)$ & & $(0.66)$ \\
\hline \multirow[t]{2}{*}{ Constant } & 2.350 & 2.220 & 3.351 & 1.960 & 2.868 & 1.817 \\
\hline & $(6.65)^{* * *}$ & $(0.94)$ & $(9.17)^{* * *}$ & $(0.79)$ & $(11.33)^{* * *}$ & $(1.08)$ \\
\hline$R^{2}$ & 0.40 & 0.40 & 0.30 & 0.31 & 0.34 & 0.35 \\
\hline$N$ & 208 & 208 & 209 & 209 & 417 & 417 \\
\hline
\end{tabular}

Table 9 shows that, by including envy among the controls, there is an increase in the size

\footnotetext{
${ }^{28}$ Notice that we perform the analysis for the whole sample.
} 
of the coefficient of $D(2,10)$ and such coefficient becomes significant also in the subsample of subjects with low wage. We interpret this as follows: the propension to envy increases the risk aversion of the individuals, and countervails the increase in risk lovingness due to the social comparison effect. The propension to envy is significantly higher in subjects from group $(2,10)$; therefore, when we perform the analysis without including envy as a control, we underestimate the effects of social comparison on the risk attitudes of subjects belonging to this group.

The analysis contained in Table 9 may however suffer from an endogeneity problem: the final questionnaire elicits the feelings of envy after the subjects know their own payoffs. Therefore, there could be an endogenous relation between the risk attitudes of a subject, his choice in the bonus task, his final payoff, and the envy he declares in the final questionnaire.

To control for this, we run a regression focusing only on subjects who have the same payoff, equal to 4.5. These are the subjects who received a low wage from the work task (i.e., 2), at the payment stage had the second part of the experiment selected and were not selected as team leader. For these subjects the risk attitudes in the bonus task did not influence the final payoff, given that the bonus task was not paid to them; therefore, the reported envy cannot be endogenous.

Table 10: Envy: Analysis for subjects with wage equal 2 and payoff equal 4.5

\begin{tabular}{|c|c|c|}
\hline \multirow[b]{2}{*}{ SCB } & \multicolumn{2}{|c|}{ wage $=$ co-worker's wage } \\
\hline & $(1)$ & $(2)$ \\
\hline \multirow[t]{2}{*}{$\mathrm{SCI}$} & 0.597 & 0.602 \\
\hline & $(7.67)^{* * *}$ & $(7.49)^{* * *}$ \\
\hline \multirow[t]{2}{*}{$\mathrm{D}(2,10)$} & -0.226 & -0.253 \\
\hline & $(0.86)$ & $(0.93)$ \\
\hline \multirow[t]{2}{*}{ envy } & 0.218 & 0.220 \\
\hline & $(2.12)^{* *}$ & $(2.10)^{* *}$ \\
\hline \multirow[t]{2}{*}{ age } & & 0.011 \\
\hline & & $(0.30)$ \\
\hline \multirow[t]{2}{*}{ gender } & & 0.170 \\
\hline & & $(0.55)$ \\
\hline \multirow[t]{2}{*}{ height } & & 0.003 \\
\hline & & $(0.22)$ \\
\hline \multirow[t]{2}{*}{ Constant } & 2.059 & 1.084 \\
\hline & $(3.78)^{* * *}$ & $(0.35)$ \\
\hline$R^{2}$ & 0.42 & 0.42 \\
\hline$N$ & 96 & 96 \\
\hline
\end{tabular}

From the analysis of the results contained in Table 10 it is possible to see that the effect of envy is indeed to significantly increase the risk aversion of the subjects.

\subsection{Inequity aversion}

To interpret the influence of social comparison on risk taking behavior, we could alternatively adopt the perspective of a model with inequity aversion. The traditional functional form of 
inequity averse preferences introduced by Fehr and Schmidt (1999), adapted to our context with two reference points, would become:

$$
v(x, r, s)=u(x-r)-\alpha \max \{s-x, 0\}-\beta \max \{x-s, 0\}
$$

where $\beta \leq \alpha$ and $\beta \in[0,1)$. This specific model of inequity aversion, that has been extensively use to interpret experimental data, cannot explain our results, as the component that depends on the social comparison is linear, and therefore it does not influence the risk attitudes of individuals. Thus, it cannot explain the empirical variation that we find in subjects' risk attitudes across social situations.

If one assumes that the social component of the above utility function has a convex or concave curvature it is possible under some specific parametric assumptions to explain the comparative statics that we find. ${ }^{29}$

A second objection to the possible interpretation of our findings in terms of inequity aversion can be derived by the analysis of subjects' self-reported happiness as it can be found in the final questionnaire. We focus on the subset of subjects ${ }^{30}$ who have been paid for the second part of the experiment, the one with social comparison, and who received a final payoff higher than their co-worker's one. For these subjects we regress self-reported happiness on the co-worker's payoff, controlling for own payoff, and for the status of team leader. ${ }^{31}$

Table 11: Effect of payoff and co-worker's payoff on happiness

\begin{tabular}{lc}
\hline Happiness & \\
\hline payoff & 0.101 \\
& $(4.07)^{* * *}$ \\
co-worker's payoff & -0.083 \\
& $(3.06)^{* * *}$ \\
team leader & 0.414 \\
& $(1.87)^{*}$ \\
Constant & 1.622 \\
& $(4.51)^{* * *}$ \\
$R^{2}$ & 0.16 \\
$N$ & 189 \\
\hline$* p<0.1 ; * * p<0.05 ;{ }^{* * *} p<0.01$
\end{tabular}

In Table 11 we see that, as expected, happiness is increasing both in own payoff and in the team leader status; it is however decreasing in the co-worker's payoff. This contradicts, for

\footnotetext{
${ }^{29}$ Notice, however, that the risk behavior of the inequity averse utility function does not depend uniquely on the curvature of the function itself, or on the relation between the curvature of $G(\cdot)$ and $u(\cdot)$; instead, it is also particularly sensitive to the relation between the first derivative of the social component and the first derivative of the individual component of the utility; therefore, in order to use inequity aversion to explain the data, we should also assume that the variation among the subjects in terms of all these relations is negligible, as the data show a robust pattern of relation between risk attitudes and social comparison.

${ }^{30}$ We consider subjects characterized by any possible risk attitude.

${ }^{31}$ The self-reported happiness experienced by subjects is derived by question (12) from the final questionnaire; subjects are asked to state how much happiness among other emotions describes their feeling in the bonus task, where the possible answer go from "not at all" (coded as 1) to "perfectly" (coded as 5).
} 
our data, an interpretation that considers inequity aversion as the main driver of the relation between utility and social comparison: concerns for inequity aversion, in fact, would predict that subjects who earn more than their co-worker have, keeping everything else equal, a higher utility the higher is their co-worker's payoff, while we find an empirical relation that goes in the opposite direction.

\subsection{Risk lovers}

We performed the main analysis both for the whole pool of subjects and for subjects who displayed risk averse (or possibly risk neutral) behavior in the risk elicitation task of the first part of the experiment. For the sake of completeness, we replicate in the Appendix the same analysis for the group of subjects who displayed risk loving behavior in the risk elicitation task.

Our theoretical analysis does not deliver predictions for decision makers characterized by a convex individual component $u(\cdot)$; however, if we extended the analysis of the theoretical results, we would find that a $G(\cdot)$ function compatible with the usual prospect theory assumptions, would induce, for prospects with social gains, the same pattern as with a concave $u(\cdot)$ : there should be more risk averse behavior in subjects facing small social gains as compared to subjects facing large social gains. The theoretical results would be, however, inconclusive for social losses, as they would depend on the relation between the degree of risk lovingness of $u(\cdot)$ and of $G(\cdot)$.

It is possible to notice from Table 12 that the comparative statics of risk lovers are similar to the comparative statics of the other subjects. Tables 15 and 16 contained in the Appendix show that this seems indeed to be the case also in a more accurate analysis, even though the small sample size of risk loving subjects implies that the relation between risk attitudes and social comparison is no longer significant.

Table 12: Risk lovers: Descriptive statistics

\begin{tabular}{lrrcr}
\hline Group & Mean & Std. Err & $95 \%$ Conf. Int. & Obs. \\
\hline$(2,2)$ & 4.85 & .46 & {$[3.90,5.79]$} & 13 \\
$(2,10)$ & 4.73 & .35 & {$[4.02,5.45]$} & 19 \\
$(10,2)$ & 4.72 & .24 & {$[4.24,5.21]$} & 18 \\
$(10,10)$ & 4.9 & .28 & {$[4.33,5.47]$} & 20 \\
\hline
\end{tabular}

\section{Discussion and conclusions}

In this paper, we analyzed the influence that social comparison may have on the risk attitudes of decision makers, with a particular attention to the effects on the risky decisions taken by subjects acting in a social environment like a workplace. We found that the social situation in which the decision maker finds himself when he faces a risky decision does indeed affect his choice; moreover, we found that individuals appear on average more risk averse in a situation of small social gains, than they are when they face social losses or large social gains. At the beginning of the paper we provided a theoretical framework, characterized by two additive components, one depending on the distance between outcomes and an individual reference point, and one depending on the distance between outcomes and a social reference point, that helps us to interpret such results. 
The analysis performed in the previous sections suggests that the experimental evidence is consistent with our theoretical framework; we admit however that we did not provide a formal test of our model, and that there may be alternative models that may explain some of our results. In particular, there is an alternative explanation that we cannot fully exclude: it could be that workers' risk attitudes depend not on the relative position of their final outcomes with respect to their social referents, but to the initial inequity between their position (i.e., their wage) and their co-worker's position (i.e., the co-worker's wage). In this case, our results should be re-interpreted in the following sense: the introduction of wage inequity increases the risk loving behavior of the workers, both in the case in which the worker benefits from the wage inequity and in the case in which the worker is damaged by it. A unique interpretation of this phenomenon, that can explain the behavior in both regions, is difficult to find. However, this effect could be the composition of two separate effects: in the social losses regions, as in our model, the worker may become more risk lover (less risk averse) to try to minimize the social loss; on the opposite side, when facing wage inequity that benefits him, and that cannot be reverted by any of the choices that he makes, a worker may feel that he can choose the risky lottery more easily, because his position in the ranking is already safe.

Our design does not allow us to fully exclude such alternative interpretations. However, it is hard to find a model that explains at the same time our empirical findings on subjects who suffer disadvantageous wage inequity and on subjects who enjoy advantageous wage inequity. Our theoretical model provides instead a unique explanation for the experimental evidence regarding the behavior of subjects across all four wage groups.

Another issue that deserves some discussion is the relation between our results and the evidence found by Linde and Sonnemans (2012) in the experimental work that is closest to our paper. The authors investigate in their experiment the possible link between social comparison and risk attitudes, as we do, and find a monotone ordering of their social situations: their data suggest that risk aversion decreases moving from social losses to a neutral setting, and decreases even more in presence of social gains.

Their "neutral" treatment is not directly comparable with our results, as in such treatment the subject determines which lottery will be played not only for himself but also for the other person (which corresponds in their setting to our co-worker). However, even excluding the neutral setting from the comparative statics, their results differ from ours, as in their data risk aversion is higher in social losses than in social gains; we find instead that risk aversion in social losses and in large social gains is not distinguishable and significantly smaller than in small social gains.

There are few main differences in the two experimental designs that may explain the difference in the results, and that may provide interesting insights for further investigation on the existing links between social comparison and risk attitudes.

First of all, the risk elicitation method and the empirical strategy differ among the two experimental studies. We use an MPL format in which subjects face only one social situation; given this method, we perform a between subjects analysis. Subjects in the experiment conducted by Linde and Sonnemans, instead, face 42 choice situations randomly spread across social gains and social losses; this allows Linde and Sonnemans to perform a within subject analysis. Moreover, the two experiments differ substantially in the tasks that precede the risk elicitation task.

These aspects of the design may influence the resulting link between social comparison and risk attitudes by inducing a different emotional status in the subjects. We discussed in Section 
5.1 how a more envious attitude is significantly correlated with a higher risk aversion, and how this attitude is more likely to occur in social losses. Some of the specific features of the experiment conducted by Linde and Sonnemans, in particular, the fact that the subjects face both gains situations and loss situations, may induce a higher degree of envy in the subjects when they face a loss situation; this could explain the different comparative statics across social situations derived from the two experimental designs.

In this paper we chose to focus on the effects that social comparison per se has on the decision makers' risk attitudes. For this reason, we investigated the choices of subjects in social situations that involved individual gains and either social gains or social losses. Our future research is therefore oriented in two directions. First of all we want to analyze the behavior of subjects who also face prospects that may revert the social ordering, that is prospects that have outcomes both in the social gains and in the social losses domain. This, in comparison with the results of this paper, should allow us to disentangle the pure effects of social comparison from the effects on risk aversion that are induced by the decision maker's desire of improving his position in the social ranking. Moreover, considering prospects with a mixed social domain should allow us to study the possible presence of social loss aversion.

Secondly, we want to analyze more deeply the interaction between the two reference points, the individual and the social one, to understand how internal habits and external habits jointly influence the decision making process. In order to do so, we plan to run further experiments in which we will have subjects facing also prospects that display individual losses and social gains, or individual losses and social losses.

Further elaborating on the mechanisms through which social comparison affects risk attitudes may prove a fruitful avenue of future research, as risk taking behavior can have a relevant economic impact. Our experimental work emphasized that, besides being an important aspect in the well-being of economic agents and having important behavioral implications in labor relations settings (e.g., effort and performance), social comparison is also a determinant of risk taking behavior. In particular, we concluded that large differences in workers' earnings can produce more risk loving behavior. Hence, we suggest that social comparison is a possible channel to control for the excessive risk taking that has been largely observed in investment banks and aknowledged as one of the possible causes of the financial crisis. The bonus component of the bankers' pay constitutes a strong incentive to choose risky investments, which increase short term performance, but are harmful for the investment bank stability. Recently, there has been much attention on which are the optimal managers' payment schemes that can help in reducing the risks assumed by the investment banks. As the Federal Reserve Board emphasizes in the Guidance on Sound Incentives Compensation Policies (2010), the payment scheme of investment banks employees should "provide employess incentives that appropriately balance risk and reward" (Federal Register, 2010, Vol. 75, No. 122) Social comparison constitutes one of the possible non-monetary incentives on which investment banks can rely to control for excessive risk taking. 


\section{A Proofs}

In the following proofs we study the sign of the derivative of $R A(x ; r, s)$ with respect to $s$ which is:

$$
\frac{\partial R A(x ; r, s)}{\partial s}=-\frac{-\gamma G^{\prime \prime \prime}\left(u^{\prime}(x-r)+\gamma G^{\prime}(x-s)\right)+\gamma G^{\prime \prime}\left(u^{\prime \prime}(x-r)+\gamma G^{\prime \prime}(x-s)\right)}{\left(u^{\prime}(x-r)+\gamma G^{\prime}(x-s)\right)^{2}} .
$$

Its sign depends on the sign of: $G^{\prime \prime \prime}\left(u^{\prime}(x-r)+\gamma G^{\prime}(x-s)\right)-G^{\prime \prime}\left(u^{\prime \prime}(x-r)+\gamma G^{\prime \prime}(x-s)\right)$.

\section{A.1 Proof of Proposition 3}

Proof. If $G(\cdot)$ is linear, $G^{\prime \prime \prime}(\cdot)=G^{\prime \prime}(\cdot)=0$; therefore $\frac{\partial R A(x ; r, s)}{\partial s}=0$

\section{A.2 Proof of Proposition 4}

\section{Proof.}

(i) If $G(\cdot)$ is CARA, then $\frac{\partial R A^{G}(x-s)}{\partial(x-s)}=0$, which implies that $G^{\prime \prime \prime}(x-s)=\frac{\left(G^{\prime \prime}(x-s)\right)^{2}}{G^{\prime}(x-s)}$. Therefore, the sign of $\frac{\partial R A(x ; r, s)}{\partial s}$ coincides with the sign of

$$
\frac{\left(G^{\prime \prime}(x-s)\right)^{2}}{G^{\prime}(x-s)}\left(u^{\prime}(x-r)+\gamma G^{\prime}(x-s)\right)-G^{\prime \prime}(x-s)\left(u^{\prime \prime}(x-r)+\gamma G^{\prime \prime}(x-s)\right) .
$$

Given that $G(\cdot)$ is convex (i.e., $G^{\prime \prime}(x-s)>0$ ) and given our assumptions on $u(\cdot)$ (i.e., $u^{\prime}(x-r)>0$ and $\left.u^{\prime \prime}(x-r)<0\right)$, the last expression is positive for every $x, r$ and $s$.

(ii) If $G(\cdot)$ is DARA, then $\frac{\partial R A^{G}(x-s)}{\partial(x-s)}<0$, which implies that $G^{\prime \prime \prime}(x-s)>\frac{\left(G^{\prime \prime}(x-s)\right)^{2}}{G^{\prime}(x-s)}$. It follows that:

$$
\begin{aligned}
& G^{\prime \prime \prime}\left(u^{\prime}(x-r)+\gamma G^{\prime}(x-s)\right)-G^{\prime \prime}\left(u^{\prime \prime}(x-r)+\gamma G^{\prime \prime}(x-s)\right)> \\
& \quad \frac{\left(G^{\prime \prime}(x-s)\right)^{2}}{G^{\prime}(x-s)}\left(u^{\prime}(x-r)+\gamma G^{\prime}(x-s)\right)-G^{\prime \prime}(x-s)\left(u^{\prime \prime}(x-r)+\gamma G^{\prime \prime}(x-s)\right),
\end{aligned}
$$

whereby, given our assumptions on $G(\cdot)$ and $u(\cdot)$, the right-hand side is positive for every $x, r$ and $s$.

\section{A.3 Proof of Proposition 5}

\section{Proof.}

(i) If $G(\cdot)$ is CARA, then $\frac{\partial R A^{G}(x-s)}{\partial(x-s)}=0$, therefore the sign of $\frac{\partial R A(x ; r, s)}{\partial s}$ coincides with the sign of

$$
\frac{\left(G^{\prime \prime}(x-s)\right)^{2}}{G^{\prime}(x-s)}\left(u^{\prime}(x-r)+\gamma G^{\prime}(x-s)\right)-G^{\prime \prime}(x-s)\left(u^{\prime \prime}(x-r)+\gamma G^{\prime \prime}(x-s)\right),
$$

which is positive if and only if 


$$
\frac{G^{\prime \prime}(x-s)}{G^{\prime}(x-s)}\left(u^{\prime}(x-r)+\gamma G^{\prime}(x-s)\right)-G^{\prime \prime}(x-s)\left(u^{\prime \prime}(x-r)+\gamma G^{\prime \prime}(x-s)\right)<0,
$$

given that $G(\cdot)$ is concave and, thus, $G^{\prime \prime}(x-s)<0$. By simplifying the left-hand side of inequality (9), we get that (9) holds true if and only if $-\frac{G^{\prime \prime}(x-s)}{G^{\prime}(x-s)}>-\frac{u^{\prime \prime}(x-r)}{u^{\prime}(x-r)}$, i.e., $R A^{G}(x-s)>R A^{u}(x-r)$.

(ii) If $G(\cdot)$ is DARA, then $\frac{\partial R A^{G}(x ; r, s)}{\partial(x-s)}<0$, which implies that $G^{\prime \prime \prime}(x-s)>\frac{\left(G^{\prime \prime}(x-s)\right)^{2}}{G^{\prime}(x-s)}$. Thus,

$$
\begin{aligned}
& G^{\prime \prime \prime}\left(u^{\prime}(x-r)+\gamma G^{\prime}(x-s)\right)-G^{\prime \prime}\left(u^{\prime \prime}(x-r)+\gamma G^{\prime \prime}(x-s)\right)> \\
& \quad \frac{\left(G^{\prime \prime}(x-s)\right)^{2}}{G^{\prime}(x-s)}\left(u^{\prime}(x-r)+\gamma G^{\prime}(x-s)\right)-G^{\prime \prime}(x-s)\left(u^{\prime \prime}(x-r)+\gamma G^{\prime \prime}(x-s)\right),
\end{aligned}
$$

whereby, given the concavity of $G(\cdot)$ (i.e., $G^{\prime \prime}(x-s)<0$ ), the right-hand side is positive if and only if inequality (9) holds true, i.e., $R A^{G}(x-s)>R A^{u}(x-r)$.

(iii) if $G(\cdot)$ is IARA, then $\frac{\partial R A^{G}(x ; r, s)}{\partial(x-s)}>0$, which implies that $G^{\prime \prime \prime}(x-s)<\frac{\left(G^{\prime \prime}(x-s)\right)^{2}}{G^{\prime}(x-s)}$. It follows that:

$$
\begin{aligned}
& G^{\prime \prime \prime}\left(u^{\prime}(x-r)+\gamma G^{\prime}(x-s)\right)-G^{\prime \prime}\left(u^{\prime \prime}(x-r)+\gamma G^{\prime \prime}(x-s)\right)< \\
& \quad \frac{\left(G^{\prime \prime}(x-s)\right)^{2}}{G^{\prime}(x-s)}\left(u^{\prime}(x-r)+\gamma G^{\prime}(x-s)\right)-G^{\prime \prime}(x-s)\left(u^{\prime \prime}(x-r)+\gamma G^{\prime \prime}(x-s)\right),
\end{aligned}
$$

whereby the right-hand side is negative if and only if $R A^{G}(x-s)<R A^{u}(x-r)$. 


\section{B Additional Tables}

\section{B.1 Independent variables}

Table 13 shows the summary statistics of the independent variables for the 347 subjects considered in the main analysis.

Table 13: Summary statics of the independent variables

\begin{tabular}{l|rrrcrr}
\hline Variable & Group & Mean & Std. Err. & $95 \%$ Conf. Int. & Min & Max \\
\hline SCI & all & 6.63 & .07 & {$[6.49,6.76]$} & 5 & 10 \\
& $(2,2)$ & 6.4 & .12 & {$[6.19,6.70]$} & 5 & 10 \\
& $(2,10)$ & 6.60 & .14 & {$[6.32,6.86]$} & 5 & 10 \\
& $(10,2)$ & 6.87 & .15 & {$[6.59,7.18]$} & 5 & 10 \\
& $(10,10)$ & 6.59 & .13 & {$[6.33,6.85]$} & 5 & 10 \\
\hline age & all & 24.12 & .19 & {$[23.74,24.48]$} & 18 & 41 \\
& $(2,2)$ & 23.60 & .35 & {$[22.91,24.29]$} & 19 & 34 \\
& $(2,10)$ & 24.07 & .39 & {$[23.31,24.84]$} & 20 & 41 \\
& $(10,2)$ & 24.22 & .41 & {$[23.39,25.04]$} & 19 & 39 \\
& $(10,10)$ & 24.60 & .35 & {$[23.92,25.29]$} & 18 & 34 \\
\hline height & all & 173.23 & .53 & {$[172.19,174.26]$} & 142 & 205 \\
& $(2,2)$ & 172.24 & .87 & {$[170.53,173.95]$} & 156 & 193 \\
& $(2,10)$ & 172.99 & 1.06 & {$[170.89,175.08]$} & 142 & 193 \\
& $(10,2)$ & 174.47 & 1.03 & {$[172.44,176.50]$} & 150 & 205 \\
& $(10,10)$ & 173.27 & 1.22 & {$[170.86,175.68]$} & 156 & 197 \\
\hline gender & all & .61 & .02 & {$[.56, .67]$} & 0 & 1 \\
& $(2,2)$ & .64 & .05 & {$[.53, .74]$} & 0 & 1 \\
& $(2,10)$ & .67 & .05 & {$[.57, .77]$} & 0 & 1 \\
& $(10,2)$ & .58 & .05 & {$[.48, .68]$} & 0 & 1 \\
& $(10,10)$ & .57 & .05 & {$[.46, .67]$} & 0 & 1 \\
\hline envy & all & 1.94 & .06 & {$[1.83,2.06]$} & 1 & 5 \\
& $(2,2)$ & 1.83 & .11 & {$[1.62,2.04]$} & 1 & 5 \\
& $(2,10)$ & 2.64 & .13 & {$[2.38,2.90]$} & 1 & 5 \\
& $(10,2)$ & 1.51 & .09 & {$[1.34,1.68]$} & 1 & 5 \\
& $(10,10)$ & 1.79 & .12 & {$[1.55,2.04]$} & 1 & 5 \\
\hline
\end{tabular}




\section{B.2 Envy}

Table 14 shows that subjects belonging to group $(2,2)$ and $(10,10)$ do not differ even if we include envy among the regressors.

Table 14: Envy: Wage equal to co-worker's wage

\begin{tabular}{|c|c|c|}
\hline \multirow[b]{2}{*}{ SCB } & \multicolumn{2}{|c|}{ wage $=$ co-worker's wage } \\
\hline & $(1)$ & $(2)$ \\
\hline \multirow[t]{2}{*}{ SCI } & 0.650 & 0.647 \\
\hline & $(9.23)^{* * *}$ & $(9.06)^{* * *}$ \\
\hline \multirow[t]{2}{*}{ wage } & 0.020 & 0.024 \\
\hline & $(0.96)$ & $(1.12)$ \\
\hline \multirow[t]{2}{*}{ envy } & -0.091 & -0.098 \\
\hline & $(1.14)$ & $(1.21)$ \\
\hline \multirow[t]{2}{*}{ age } & & -0.016 \\
\hline & & $(0.59)$ \\
\hline \multirow[t]{2}{*}{ gender } & & -0.047 \\
\hline & & $(0.19)$ \\
\hline \multirow[t]{2}{*}{ height } & & -0.009 \\
\hline & & $(0.63)$ \\
\hline \multirow[t]{2}{*}{ Constant } & 2.266 & 4.203 \\
\hline & $(4.67)^{* * *}$ & $(1.51)$ \\
\hline$R^{2}$ & 0.34 & 0.35 \\
\hline$N$ & 171 & 171 \\
\hline
\end{tabular}




\section{B.3 Risk lovers}

Tables 15 and 16 replicate the main analysis for subjects who display risk loving behavior in the individual risk task $(S C I<5)$.

Table 15: Risk lovers: Analysis by wage group

\begin{tabular}{|c|c|c|c|c|c|c|}
\hline \multirow[b]{2}{*}{ SCB } & \multicolumn{2}{|c|}{ wage $=2$} & \multicolumn{2}{|c|}{ wage $=10$} & \multicolumn{2}{|c|}{ all subjects } \\
\hline & (1) & $(2)$ & $(3)$ & $(4)$ & $(5)$ & $(6)$ \\
\hline \multirow[t]{2}{*}{ SCI } & 0.475 & 0.339 & -0.021 & -0.014 & 0.211 & 0.177 \\
\hline & $(1.22)$ & $(0.79)$ & $(0.08)$ & $(0.05)$ & $(0.92)$ & $(0.74)$ \\
\hline \multirow[t]{2}{*}{$\mathrm{D}(2,10)$} & -0.302 & -0.121 & & & -0.213 & -0.328 \\
\hline & $(0.51)$ & $(0.18)$ & & & $(0.53)$ & $(0.80)$ \\
\hline \multirow[t]{2}{*}{$\mathrm{D}(10,2)$} & & & -0.173 & -0.237 & -0.213 & -0.284 \\
\hline & & & $(0.45)$ & $(0.52)$ & $(0.53)$ & $(0.70)$ \\
\hline \multirow[t]{2}{*}{ age } & & -0.202 & & -0.034 & & -0.069 \\
\hline & & $(1.91)^{*}$ & & $(0.49)$ & & $(1.47)$ \\
\hline \multirow[t]{2}{*}{ gender } & & 0.921 & & -0.577 & & -0.205 \\
\hline & & $(0.84)$ & & $(1.08)$ & & $(0.41)$ \\
\hline \multirow[t]{2}{*}{ height } & & 0.043 & & -0.008 & & 0.007 \\
\hline & & $(0.61)$ & & $(0.29)$ & & $(0.26)$ \\
\hline \multirow[t]{2}{*}{ Constant } & 3.237 & 0.239 & 4.973 & 7.557 & 4.150 & 4.919 \\
\hline & $(2.33)^{* *}$ & $(0.02)$ & $(5.08)^{* * *}$ & $(1.44)$ & $(5.02)^{* * *}$ & $(0.94)$ \\
\hline$R^{2}$ & 0.05 & 0.23 & 0.01 & 0.05 & 0.02 & 0.06 \\
\hline$N$ & 32 & 32 & 38 & 38 & 70 & 70 \\
\hline
\end{tabular}


Table 16: Risk lovers: Wage equal to co-worker's wage.

\begin{tabular}{lcc}
\hline & \multicolumn{2}{c}{ wage $=$ co-worker's wage } \\
\cline { 2 - 3 } SCB & $(1)$ & $(2)$ \\
\hline SCI & 0.536 & 0.400 \\
& $(1.73)^{*}$ & $(1.16)$ \\
wage & -0.001 & 0.018 \\
& $(0.02)$ & $(0.20)$ \\
age & & -0.011 \\
& & $(0.11)$ \\
gender & & -0.068 \\
& & $(0.10)$ \\
height & & -0.037 \\
& & $(0.88)$ \\
Constant & 3.033 & 10.102 \\
& $(2.64)^{* *}$ & $(1.38)$ \\
$R^{2}$ & 0.09 & 0.14 \\
$N$ & 33 & 33
\end{tabular}




\section{Supplementary material from the experiment}

\section{C.1 Instructions \\ C.1.1 General instructions}

Welcome and thank you for your participation! Please read carefully the following instructions.

Please note that it is not allowed to talk with other participants during the entire experiment. If you have any question, please raise your hand. We will come to you and answer your question personally. If you violate these rules, we are forced to interrupt the experiment. Please turn off your mobile phones from now and keep notes, books and food out of your cabin.

The experiment will last about $\mathbf{4 5}$ minutes. You will be paid a participation fee of 2,50 EURO for completing the experiment. Your final earnings today will depend on your own actions and some element of chance. Earnings will be computed in ECU (Experimental Currency Unit) where

\section{$1 \mathrm{ECU}=1$ EURO}

The experiment will consist of TWO PARTS. At the start of each part you will receive instructions about that part. Only one part will affect your final earnings: the first part has $10 \%$ of chances of being paid, while the second part has $90 \%$ of chance of being paid. At the end of the experiment, the computer will determine which part you will be paid for. Since you cannot know in advance which part will be drawn for your payment, we recommend you to focus on each part as it was the part which will determine your earnings. You will be paid in cash at the end of the experiment, after you provide your answers to a questionnaire.

\section{C.1.2 Instruction for PART I}

The first part of today experiment will consist of a decision task.

The decision task consists of ten choices between Option A and Option B; each Option is a lottery which can give you by chance either a favorable monetary outcome or an unfavorable monetary outcome. The favorable and the unfavorable outcomes of Option A and the favorable and the unfavorable outcomes of Option B are represented in a bar graph on the top of the screen. An outcome is identified by a bar whose size reflects the amount you can earn, which is also indicated with numbers in the picture.

For every Option, the favorable outcome is the larger gain (the longer bar, which is dark green $^{32}$ ), while the unfavorable outcome is the smaller gain (the shorter bar, which is light green $\left.^{33}\right)$.

\footnotetext{
${ }^{32}$ In the version of the instruction that we used in the experiment, "dark green" was written using fonts of the same dark green used in the graphs.

${ }^{33}$ In the version of the instruction that we used in the experiment, "light green" was written using fonts of the same light green used in the graphs.
} 
For example, consider the following picture, which is an example of a pair of Options:
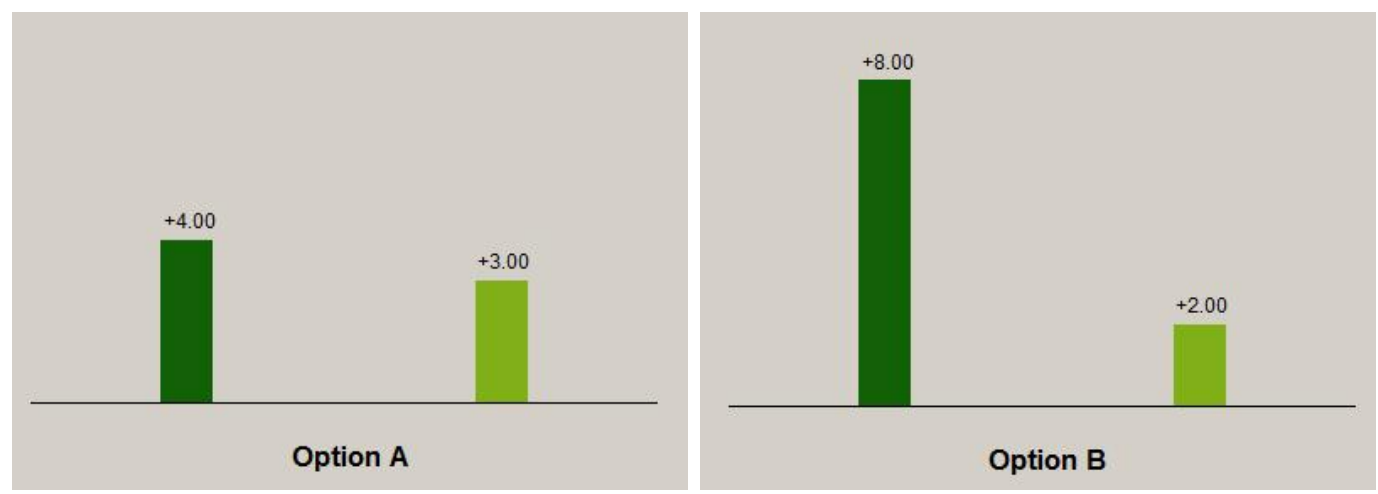

If you choose Option A, and by chance the favorable outcome occurs you gain the payoff written on the top of the dark green bar (i.e., +4 ECU). If the unfavorable outcome occurs, you gain the payoff written on the top of the light green bar (i.e., +3 ECU).

Below the bar graph you will find ten decision rows: for each row you have to make a choice between Option A and Option B. The chances of the favorable outcome and of the unfavorable outcome change across rows and are represented by pie charts. The dark green slice of the pie represents the chances of the favorable outcome and the light green slice of the pie represents the chances of the unfavorable outcome; next to each pie chart you will also see in percentage terms the chances of the favorable outcome written in dark green and the chances of the unfavorable outcome written in light green. In the row that corresponds to each pie chart you have to select either Option A or Option B by clicking on the relevant button. In the following picture, below the bar graph, you can see an example of one of the ten decision rows you will visualize in the task:
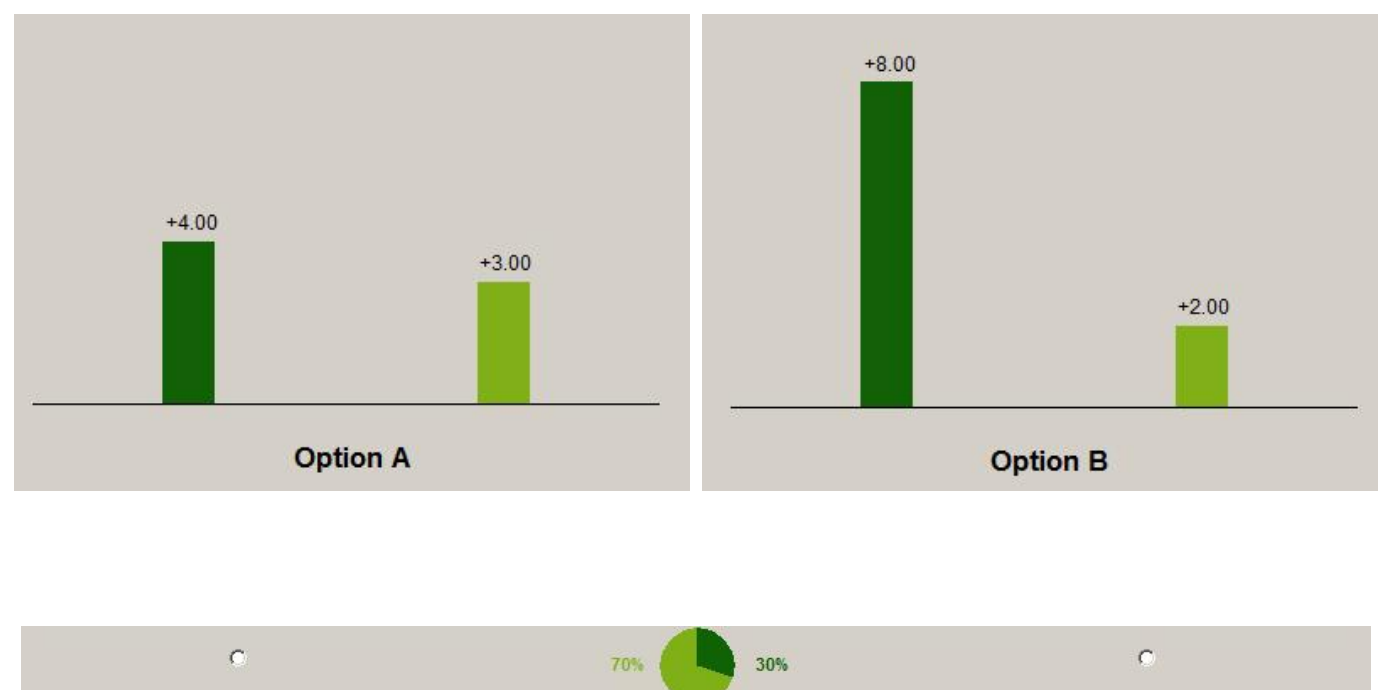

r

In this decision row, in each lottery, the favorable outcome may occur with $30 \%$ of chances and the unfavorable outcome with $70 \%$ of chances. In Option A you may get +4 ECU with $30 \%$ of chances and +3 ECU with $70 \%$ of chances. In Option B you may get +8 ECU with $30 \%$ of 
chances and +2 ECU with $70 \%$ of chances. Given this information, you have to make a choice between Option A and Option B.

To summarize you will make ten decisions between Option A and Option B. You may choose A for some decision rows and B for other rows, and you may change your decisions and make them in any order. When you are done, you have to click on the Submit button to proceed to the following part of the experiment. The computer will allow you to submit and proceed only once you made all the ten decisions.

\section{Payment of PART I}

At the end of the whole experiment, the computer will randomly select which part of the experiment will be paid out: this part has $40 \%$ of chances of being paid out.

If this first part of the experiment is selected to be paid out the computer will select by chance one of your ten decision rows: each decision row has an equal chance of being drawn. Notice that even though you will make ten choices only one of your choices will end up affecting your final earnings, but you will not know in advance which choice will be used. Each choice that you make has an equal chance of being used in the end.

Finally, the computer will play the lottery corresponding to the Option you chose for the decision row which has been drawn: Chance determines whether you will be paid the good (dark green) or the bad (light green) outcome of that Option.

\section{C.1.3 Instructions of PART II}

\section{General instructions for PART II}

In PART II of today experiment you will be paired at random with another subject, who will be your co-worker for all the rest of the experiment. Each one of you will be assigned a contract, which determines the wage you will get for performing a certain work task. Then you will perform the work task and your wages will be computed.

After your wage is determined, you have the opportunity to gain a bonus on top of this wage by performing a decision task which is very similar to the one you faced in PART I of today experiment. Indeed, in order to get a bonus, you have to choose between two projects (A and B) which have two possible realizations each: a favorable and an unfavorable monetary outcome.

\section{Detailed instructions for PART II}

\section{Your contract}

Each one of you will be assigned either Contract $\mathbf{E}$ or Contract $\mathbf{F}$ which establish your wage for the next work task. In both contracts your wage is either 2 ECU or 10 ECU depending on the result of a computerized fair coin toss. The two contracts differ in the following sense: 
- Contract E pays 10 ECU if the result of the coin toss is HEAD, while it pays 2 ECU if the result of the coin toss is TAIL.

- Contract $\mathbf{F}$ pays $\mathbf{2}$ ECU if the result of the coin toss is HEAD, while it pays 10 ECU if the result of the coin toss is TAIL.

Therefore, your wage will depend partly on your given contract and partly on chance. Suppose the result of the coin toss is HEAD: those of you with Contract E will get a wage of 10 ECU, while those of you with Contract $\mathrm{F}$ will get a wage of 2 ECU. Instead, if the result is TAIL, those of you with Contract E will get a wage of 2 ECU while those of you with Contract F will get a wage of 10 ECU. Notice that the two contracts are equivalent, the only difference being that one pays a high wage when HEAD and the other when TAIL.

\section{Work task}

This task consists of two similar parts lasting a maximum of 4 minutes each. NOTICE: If you do not complete both parts of the task within the time limits your contract will not be enforced and you will get a wage of 0 ECU for this work task!.

The first part consists of writing 20 combinations of two letters from the set of letters

$$
\mathrm{A}, \mathrm{B}, \mathrm{C}, \mathrm{D}, \mathrm{E}, \mathrm{F}, \mathrm{G}, \mathrm{H}, \mathrm{I}, \mathrm{J}
$$

which is displayed on the top of your screen.

You have to insert each combination (for example: AE, GI, FB,) in an empty box (in capital letters, without commas or spaces between the letters) and then click on the ok button. You will see 20 empty boxes (with the corresponding ok buttons next to them) arranged on two columns on your screen. You will start to fill the first column and then the second, starting from the first box at the top of the left column and ending with the last box at the bottom of the right column.

You can choose whichever combination of letters; you can also choose twice the same letter in a combination (e.g., AA). There are only two restrictions:

1) if you insert a combination which has been already inserted by your co-worker, this combination will not be validated

2) if you insert a combination you already inserted yourself, it will not be validated.

In both cases, after you press the ok button, you will receive an error message which invites you to find a new combination to fill the box with.

If instead after pressing the ok button your combination is validated, you will see a green circle on the left of the combination.

Please notice that it is very important that every time you insert a combination you press immediately the ok button, otherwise your combination cannot be validated. Also your combinations will not be validated if you do not press the confirm button at the end of the task. 
The second part of the work task is very similar to the first part, except for the set of letters you can combine: you have to fill the boxes now with 20 combinations of two letters from the new set of letters $\mathbf{K}, \mathbf{L}, \mathbf{M}, \mathbf{N}, \mathbf{O}, \mathbf{P}, \mathbf{Q}, \mathbf{R}, \mathbf{S}, \mathbf{T}$ (displayed on top of your screen). The same restrictions as above hold.

\section{Payment of the work task}

After you completed both parts of this work task, you will know the result of the coin toss (HEAD or TAIL) that determines your wage and the wage of your co-worker. You will be informed about both wages.

\section{Bonus task}

You will face now a decision task which is very similar to the one you saw in the first part of the experiment. Both you and your co-worker will face this task, however only the task of one of you will be paid out. You will receive the payment of this task, the bonus pay, only if you will be selected as the team leader. You and your co-worker have the same chances (50\%) of being selected as team leader, but you will not know in advance who will be the leader. The bonus pay will be added to the previous wage of the team leader only.

We describe the bonus task very briefly because it is very similar to the decision task of PART I. Indeed, the bonus task consists of ten choices between Project A and Project B; each Project can be successful or unsuccessful. If a Project is successful, it gives you a high bonus (represented by the dark green bar). If a Project is unsuccessful, it gives you a low bonus (represented by the light green bar). The possible bonuses from each Project are represented in a bar graph displayed on the top of the screen.

Below the bar graph you will find ten decision rows: for each row you have to make a

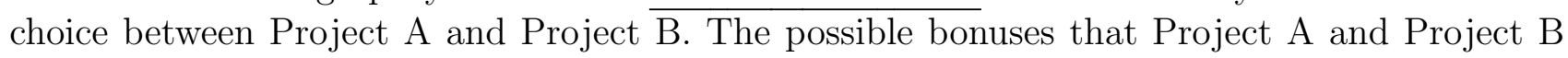
can give you are for all ten decisions those described in the bar graph; the chances of the high or the low bonuses change across rows and are described by pie charts. The dark green slice of the pie represents the chances of the high bonus and the light green slice of the pie represents the chances of the low bonus; chances in percentage terms are indicated next to each pie chart.

In the row that corresponds to each pie chart you have to select either Project A or Project $\mathrm{B}$, given the chances of the higher and lower bonuses.

As in the decision task of PART I, in the bonus task you will make ten choices: for each decision row you will have to choose between Project A and Project B. You may choose A for some decision rows and B for other rows, and you may change your decisions and make them in any order. The computer will allow you to submit and proceed only if you made all the ten decisions.

\section{Payment:}

At the end of the bonus task, the computer will randomly select which part of the experiment will be paid out to you and your co-worker: PART II has $90 \%$ of chances of being paid out. The random selection will be the same for the pair of you, so that if you are paid PART II, also your co-worker will be paid PART II. 
If PART II of the experiment is selected to be paid out the computer will select by chance either you or your co-worker to be the team leader. Each one of you has $50 \%$ of chances of being selected as team leader. Notice no choice you made in the experiment influences the selection of the team leader that is completely random.

The computer will then select by chance one of the ten decision rows of the team leaders decision task; each one of the team leaders 10 decision rows has an equal chance of being drawn.

Notice that even though you and your co-worker will make ten choices only the team leader will receive the bonus and only one choice of the team leader will determine this bonus, but none of you will know in advance who will be the team leader and which choice will be used.

Finally the computer will play the lottery corresponding to the Project that the team leader chose in the decision row which has been drawn: Chance determines whether the team leader will be paid the high (dark green) or the low (light green) bonus for that Project.

If you have been selected as the team leader, your final pay is given by the show-up fee, the wage from the work task and your realized bonus; your co-workers final pay in this case consists of the show-up fee and his/her wage only.

If you have not been selected as team leader your final pay is given by the show up fee and your wage only; your co-workers final pay in this case is given by your co-workers show up fee, his/her wage from the work task and his/her realized bonus.

You will then answer a questionnaire and get your final pay in cash. 


\section{C.2 Questionnaire}

We will keep your information strictly confidential. Please answer the following questions as much carefully and accurately as possible.

(1) How old are you?

(2) What is your gender?

(3) What is your nationality?

(4) How tall are you?

(5) What do you study?

(6) What is your weekly budget?

(7) What is your current employment situation? (Full employment outside school; Part-time employment outside school; Student only; Work at school; Other)

(8) In the last year have you bought ticket for lotteries or similars? (Never, once, once a month, more than once a month)

Please use the following scale to indicate how much you agree with the following statements:

$\begin{array}{lllll}1 & 2 & 3 & 4 & 5\end{array}$

Strongly Disagree Neutral Agree Strongly

Disagree Agree

(9) I understood the instructions (1 or 2 or 3 or 4 or 5 )

(10) The control questions were useful (1 or 2 or 3 or 4 or 5 )

(11) The bonus task of PART II was more difficult than the decision task of PART I of the experiment

(12) Please indicate how well each of the following emotion describes your feelings during the $\begin{array}{cccccc}\text { bonus tasks: } & 1 & 2 & 3 & 4 & 5 \\ & \text { Not at all } & \text { Very badly } & \text { Rather well } & \text { Very well } & \text { Perfectly }\end{array}$

- Envy (1 or 2 or 3 or 4 or 5 )

- Gloat (1 or 2 or 3 or 4 or 5 )

- Anger (1 or 2 or 3 or 4 or 5 )

- Happiness (1 or 2 or 3 or 4 or 5 )

(13) What did it matter more in the second part of the experiment: the comparison of your wage ( 2 or 10 ECU) with the wage of your co-worker (2 or 10 ECU) or the comparison of your wage with the average wage that the subjects got in today experiment (6 ECU)? (the comparison with your co-workers wage, the comparison with the average wage of all subjects, none matters)

(14) Please leave your comments on how to improve our experiment! 


\section{References}

[1] Bolton, G.E., Ockenfels A., 2010, Betrayal aversion: Evidence from Brazil, China, Oman, Switzerland, Turkey, and the United States: Comment. American Economic Review, 100, 628-633.

[2] Card, D., Mas A., Moretti E., Saez E., 2012, Inequality at work: the effect of peer salaries on job satisfaction, American Economic Review, 102(6), 2981-3003.

[3] Charness, G., Kuhn P., 2007, Does pay inequality affect worker effort? Experimental evidence, Journal of Labor Economics, 25(4), 693-723.

[4] Clark, A.E., Masclet D., Villeval M.C., 2010, Effort and comparison income. Experimental and survey evidence, Industrial and Labor Relations Review, 63(3), 407-426.

[5] Clark, A.E., Oswald A.J., 1996, Satisfaction and comparison income, Journal of Public Economics, 61(3), 359-381.

[6] Clark, A.E., Oswald A.J., 1998, Comparison-concave utility and following behaviour in social and economic settings, Journal of Public Economics, 70, 133-155.

[7] Cohn, A., Fehr E., Herrmann B., Schneider F., 2011, Social comparison in the work place: Evidence from a field experiment, IZA Working Paper.

[8] Duesenberry, J.S., 1949, Income, saving and the theory of consumer Behavior, Harvard University Press, Cambridge, Massachussets.

[9] Schwerter, F., 2013, Social reference points and risk taking, Bonn Discussion Papers.

[10] Fafchamps, M., Bereket, K., Zizzo, D.J., 2013, Keep up with the winners: Experimental evidence on risk taking, asset integration and peer effects, CEPR Discussion Paper No. DP9714.

[11] Fehr, E., Schmidt, K., 1949, A Theory of fairness, competition and cooperation, Quarterly Journal of Economics, 114(3), 817-851.

[12] Ferrer-i-Carbonell, A., 2005, Income and well-being: An empirical analysis of the comparison income effect, Journal of Public Economics, 89(5-6), 997-1019.

[13] Festinger, L., 1954, A theory of social comparison processes, Human Relations, 7, 117-140.

[14] Fischbacher, U., 2007, z-Tree: Zurich toolbox for ready-made economic experiments, Experimental Economics, 10(2), 171-178.

[15] Greiner, B., 2004, The online recruitment system ORSEE 2.0 - A guide for the organization of experiments in Economics, University of Cologne, Working Paper Series in Economics 10.

[16] Harrison, G.W., Johnson E., McInnes M.M., Rutstrom E.E., 2005, Risk aversion and incentive effects: comment, American Economic Review, 95(3), 897-901.

[17] Holt, C.A., Laury S.K., 2002, Risk aversion and incentive effects, American Economic Review, 92(5), 1644-1655. 
[18] Kahneman, D., Tversky A., 1979, Prospect theory: an analysis of decision under risk, Econometrica, 47, 263-291.

[19] Koop, G.J., Johnson J.G., 2010, The use of multiple reference-points in risky decision making, Journal of Behavioral Decision Making, 25, 49-62.

[20] Koszegi, B., Rabin M., 2006, A model of reference-dependent preferences, Quarterly Journal of Economics, 121(4), 1133-1165.

[21] Koszegi, B., Rabin M., 2007, Reference-dependent risk attitudes, American Economic Review, 97(4), 1047-1073.

[22] Kroll, Y., Davidovitz L., 2003, Inequality aversion versus risk aversion, Economica, 70, 19-29.

[23] Laury, S.K., Holt C.A., 2000, Further Reflections on Prospect Theory, mimeo.

[24] Linde, J., Sonnemans J.H., 2012, Social comparison and risky choices, Journal of Risk and Uncertainty, 44, 45-72.

[25] March, J.G., Shapira Z., 1992, Variable risk preferences and the focus of attention, Psychological Review, 99, 172-183.

[26] Maccheroni, F., Marinacci M., Rustichini A., 2012, Social decision theory: choosing within and between groups, The Review of Economic Studies, 79(4), 1591-1636.

[27] Office of the Comptroller of the Currency, Board of Governors of the Federal Reserve System, Federal Deposit Insurance Corporation, Office of Thrift Supervision, 2010, Guidance on sound incentives compensation policies, Federal Register, Vol. 75(122).

[28] Ok E. A., Koçkesen, L., 2000, Negatively interdependent preferences, Social Choice and Welfare, 17, 533-558.

[29] Ockenfels A., Sliwka, D., Werner P., 2010, Bonus payments and reference point violations, IZA Working Paper.

[30] Ordonez, L.D., Connolly T., Coughlan R., 2000, Multiple reference points in satisfaction and fairness assessment, Journal of Behavioral Decision Making, 13, 329-344.

[31] Rohde, I.M.T., Rohde K.I.M., 2011, Risk attitudes in a social context, Journal of Risk and Uncertainty, 43, 205-225.

[32] Sullivan, K., Kida T., 1995, The effect of multiple reference points and prior gains and losses on managers' risky decision making, Organizational Behavior and Human Decision Processes, 64, 76-83.

[33] Veblen, T., 1899, The theory of the leisure class, Macmillan, New York.

[34] Vendrik, M., Woltjer G., 2007, Happiness and loss aversion: Is utility concave or convex in relative income?, Journal of Public Economics, 91(7-8), 1423-1448.

[35] Wang, X.T., and J.G. Johnson (2012), A tri-reference point theory of decision making under risk, Journal of Experimental Psychology: General, 141(4), 743-756. 